\title{
Price Regulation of Access to Telecommunications Networks
}

By

Ingo Vogelsang ${ }^{1}$

${ }^{1}$ Department of Economics, Boston University. The author would like to thank the New Zealand Institute for the Study of Competition and Regulation for the permission to use a previous study (Vogelsang 2000) on which this survey is based. My deep thanks for helpful comments go to Lewis Evans, Larry Kotlikoff, John McMillan, Bridger Mitchell, Glenn Woroch and two insightful referees. 


\section{Introduction}

As a result of competition the telecommunications sector today consists of a myriad of networks. Also, many telecommunications service providers own partial networks. With the exception of private networks, all of these have access to each other or are interconnected to form a network of networks that is usable by all service providers. Without access and interconnection such networks and competition between them would hardly have spread so quickly. Here, interconnection shall mean that two networks are linked to provide call origination, transit and termination for each other and the networks operate at the same level of network hierarchy. In contrast, access refers to the case, where the networks operate at different hierarchical levels and only one network uses the other to originate or terminate calls.

Access and interconnection benefit consumers and the competitive process. They are necessary for carriers to provide ubiquitous service and enable end-users to call anybody and be called by anybody (the any-to-any principle) without having to sign up with a system-wide network monopolist. Being able to be called by or call more people increases a subscriber's utility and thereby provides a network externality that access and interconnection help secure. Access and interconnection also help reduce market power. They lower barriers to entry, because entrants need not establish full-coverage networks. Furthermore, in the absence of access and interconnection, owners of narrow monopolies could make use of network externalities (and economies of scope) to leverage their market power into other telecommunications markets. In contrast, interconnection could, among sufficiently symmetric competing networks, also provide incentives for collusion.

Access and interconnection are indispensable for the functioning of a competitive telecommunications market. However, to the extent that they create network externalities, the market is likely to provide too little of them. In addition, the originally dominating network providers have few incentives to give competitors access to their facilities, especially to those that are hard or impossible to duplicate. ${ }^{2}$ Antitrust policy could deal with such bottleneck issues in principle, but actually implementing the so-called "essential facilities doctrine" involves 
ongoing supervision and pricing assessments that resemble regulation. In an already regulated telecommunications sector such additional regulation therefore comes naturally. Today, access and interconnection pricing are a paramount policy concern of telecommunications regulators.

Historically, network access and network interconnection were important issues in telecommunications almost right from the start. Once long-distance telephony was feasible, networks had to be interconnected to provide end-to-end services. While such interconnection between adjacent networks is still important internationally, we concentrate on interconnection between telecommunications carriers that compete with each other and access of a carrier to the network of another. That interconnection and access are the key to competition in telecommunications became abundantly clear after the expiration of the original Bell patents, when competing networks emerged that were not interconnected. As a result, subscribers on the other networks could not be reached, forcing businesses to subscribe to several networks in order to reach their customers and be reachable by them. This was not a tenable long-run situation. However, it persisted until AT\&T bought up patents for the best viable technology for longdistance services and refused to interconnect with its local rivals. As a result, the local rivals could not offer the same long-distance services as AT\&T. Lack of interconnection thereby foreclosed the rivals and AT\&T rapidly regained lost market shares. Thus, the lack of interconnection emerged as the major barrier to telecommunications competition and may have led to the subsequent regulation. Not surprisingly, when network competition reemerged in the 1970s, the legal battlefields were about access and interconnection. Again, AT\&T refused to let the new rivals use its network for completion and origination of calls that would travel longdistance over the rivals' networks. Rather, it was access regulation that jump-started competition.

Economists and economic ideas have had a large and sometimes conflicting impact on access and interconnection pricing policies. Examples include the Baumol-Willig efficient component pricing rule, which made headlines and was eventually rejected in New Zealand, while the controversial pricing method designed by FCC economists for unbundled network elements was

\footnotetext{
${ }^{2}$ While incumbents with almost $100 \%$ market share have little to gain from the network externalities provided by entrants, entrants have everything to gain from the network externalities provided by the incumbent.
} 
confirmed in a recent US Supreme Court decision. The current survey shows how policy issues such as these are grounded in microeconomic concepts and ideas. ${ }^{3}$

\section{One-way Access}

\subsection{Introduction}

The structure of this review emphasizes the difference between an access model and an interconnection model or, in more accepted language, between one-way access and two-way access. ${ }^{4}$ One way access (or the access model) concerns the provision of bottleneck inputs by an incumbent network provider to new entrants, while two-way access (or the interconnection model) concerns reciprocal access between two networks that have to rely upon each other to terminate calls. The distinction arose for two reasons. First the one-way access problem is the provision of a monopoly input by a vertically separated or a vertically integrated monopolist, while the two-way access problem is the coordination of an essential input between two firms in more or less symmetric situations. Second, as competition in the telecommunications industry matures, the two-way access problem becomes increasingly relevant as it has always been between geographically separated monopolies. Although this development suggests that fully facilities-based competition could emerge from one-way access relationships, this dynamic and long-term aspect of one-way access is not really captured in the literature.

The one-way access problem concerns an upstream bottleneck input owned by a vertically integrated dominant incumbent operator (“incumbent") and essential for non-integrated entrants competing with the incumbent in a downstream market. The one-way access problem is closely linked to the essential facilities doctrine in antitrust. It becomes an antitrust or regulatory problem if the nonintegrated firms cannot reasonably duplicate the bottleneck facility and if the

\footnotetext{
${ }^{3}$ Compared to prior surveys by Jean-Jacques Laffont and Jean Tirole (2000) and Mark Armstrong (2002), who both use a unified and formal theoretical approach, the current survey aims at the policy relevance of theoretical results and the gaps in the literature, when it comes to policy applications.

${ }^{4}$ Noam (2002) calls one-way access vertical interconnection and two-way access horizontal interconnection if it involves competing networks or parallel interconnection if it involves noncompeting networks. This survey concentrates on horizontal and vertical interconnection.
} 
integrated firm is not willing to let them use it at reasonable terms. The network externality makes bottlenecks particularly troublesome in telecommunications because localized bottlenecks could be used effectively to exclude competitors from large markets. This would be less so under vertical separation, which turns the bottleneck issue into one of fairly straightforward input monopoly and which has some empirical relevance, particularly after the 1984 AT\&T divestiture. Regulation of long-distance access charges of the divested Bell Operating Companies nevertheless remained controversial because of cost allocation and crosssubsidization issues.

\subsection{Pricing Rules}

\subsubsection{Optimal regulation of access and retail: Ramsey prices}

From the perspective of policy makers, access charges could help achieve a number of tasks, such as encourage the right amount of downstream entry and upstream bypass, encourage efficient network investment and network utilization, while being manageable. The tasks are conveniently aggregated in social surplus under the Ramsey approach to access pricing taken by Jean-Jacques Laffont and Jean Tirole (1993 and 1994). Ramsey prices maximize welfare subject to a break-even constraint on the regulated firm(s). Originally, they had been developed by Marcel Boiteux (1956) and William Baumol and David Bradford (1971) in the context of multiproduct end-user pricing, leading to the familiar inverse (super-) elasticity rule. ${ }^{5}$ It extends naturally to the case of an input monopolist, offering multiple inputs that are used in fixed proportions by a perfectly competitive downstream industry. In a more realistic setting, what distinguishes the access pricing problem under vertical separation from a retail Ramsey pricing problem is that downstream competition may not be perfect so that demands for intermediate inputs cannot simply be interpreted as end-user valuations for the downstream outputs. The optimal access-pricing problem therefore has to make adjustments for imperfect competition

\footnotetext{
${ }^{5}$ In contrast to regular price elasticities that only capture the price effects in a single market, super-elasticities include all the cross effects of a price change. They can therefore be quite complicated. The introduction of superelasticities into Ramsey formulas is due to Jeffrey Rohlfs (1979).
} 
downstream. In case of downstream market power, optimal access price regulation has to strike a balance between compensating for downstream markups by lowering access charges and inducing inefficient downstream entry (Mark Armstrong, Simon Cowan and John Vickers 1994, Section 5.2.1). Such entry incentives could be counteracted by two-part access charges with variable fees below marginal costs and fixed fees to cover the total costs of access (Laffont and Tirole 2000, Section 2.2.5). While being more complicated than the end-user Ramsey problem, under vertical separation there is no inherent conflict of interest between access provider and access seeker. In this sense, vertical separation via divestiture "solves" the access problem and facilitates regulation of access prices. On the other hand, separation can be marred by double marginalization and loss of scope economies (Koji Domon and Koshiro Ota 2001). ${ }^{6}$

In contrast, the Ramsey approach under vertical integration simultaneously determines optimal access and final goods prices, based on assumptions about demand relationships, technology and type of competition. The approach leads to potentially complex results, as they incorporate the incumbent's budget constraint, demand relationships, cost relationships and types of competition. This complexity reflects the complicated nature of the problem and is the price to be paid for general rather than partial optimization. While homogeneous dominant firm/competitive fringe competition leads to more familiar inverse derived demand (super-) elasticity markups for access charges (Laffont and Tirole 1993), Cournot competition between the entrant and incumbent in the retail market yields access prices with the following components (Hautam Masmoudi and Francois Prothais 1994):

1. the marginal cost of access,

2. a Ramsey markup, consisting of inverse (super-) elasticities, market shares and the type of competitive interaction,

3. an access charge elasticity term relating the access charge to the entrant's output. This term brings out that the entrant's demand for access is a derived demand. The less elastic the demand for the entrant's output is to the access charge the higher the access charge should be.

\footnotetext{
${ }^{6}$ Double marginalization refers to downstream markups that are put on top of upstream markups if both stages in a vertical production chain are affected by market power.
} 
4. a differential efficiency term reflecting the difference in efficiency between the incumbent and the entrant in providing the final good. This term has two opposing components: The more efficient the entrant the more it should produce relative to the incumbent, thus the lower the access price. Conversely, the more stringent the incumbent's budget constraint the less weight is given to the entrant's efficiency.

A particular role in the second term above is played by the displacement ratio or business stealing effect - the negative of the marginal change in the incumbent's output over the marginal change in the entrant's output as a result of a marginal access price change. This expression, due to Mark Armstrong, Chris Doyle and John Vickers (1996), condenses the demand relationship between the incumbent's and the entrant's outputs and the type of competition between the two. If the entrant has bypass opportunities the displacement ratio can be extended to include these. In this case, some productive inefficiency would result from the inability of the incumbent to fully price discriminate access (Armstrong 2002).

In addition to access charges, the optimal final goods prices themselves obey a complicated markup formula. While regulators could try and approximately implement such global Ramsey pricing formulas, there have been no known attempts to do so. This may be as much attributable to interest group influences opposed to the resulting markups as to lack of information about elasticities, costs and competitive reactions and the inability to solve complex conceptual problems. Economists and practitioners have therefore proposed simpler ways to determine access charges (and final goods prices) with desirable properties, including:

- the efficient component-pricing rule (ECPR),

- cost-based access charges,

- price caps for access and/or end-users,

- deregulation of end-user prices. 


\subsubsection{The Efficient Component Pricing Rule (ECPR)}

\subsubsection{The simple ECPR}

Although its practical impact has paled compared to cost-based access charges, the BaumolWillig efficient component-pricing rule (ECPR) remains the access-pricing rule most hotly discussed in the literature. ${ }^{7}$ It says the incumbent should charge an access price equal to the average incremental resource costs of access plus the so-called "opportunity cost" of access. This opportunity cost is the foregone profit contribution of the incumbent by providing access to a competitor who might use access to displace services provided by the incumbent. It also equals the "second-best output tax on entry" (Armstrong 2002) provided the end-user price is the one desired by the regulator. The efficient component price can finally be derived by deducting the incremental costs of the downstream activity from the incumbent's retail price. Thus, the ECPR is driven by the incumbent's retail prices.

If (a) access and final outputs are generated in fixed proportions and if (b) the incumbent's and the entrants' final outputs are perfect substitutes and if (c) entrants take the incumbent's price of the competing final output as given, then the opportunity cost is simply the profit contribution or quasi-rent generated by the incumbent's final output (simple ECPR or margin rule). The only function of competitive entry therefore becomes to provide the downstream part of the network service at lower cost than the incumbent. Then the ECPR assures that entry occurs if and only if an entrant, who cannot bypass the incumbent's network, is more efficient than the incumbent in the downstream stage. ${ }^{8}$ The ECPR is therefore a partial rule that deals only with a specific aspect of network pricing and competition. The reasons for its publicity are that, in the simple version of the margin rule,

- it is easily understood and practiced,

\footnotetext{
${ }^{7}$ The ECPR is widely attributed to Robert Willig (1979) and William Baumol (1983). See, however, William Baumol, Janusz Ordover, and Robert Willig (1997), who attribute the rule solely to Willig (1979). For an extensive discussion, see William Baumol and Gregory Sidak (1994) and the Winter 1994 edition of The Yale Journal on Regulation and in the Fall 1995 issue of the Antitrust Bulletin.

${ }^{8} \mathrm{~A}$ marginal cost ECPR based on marginal rather than average incremental costs would provide better incentives at the margin than an average incremental cost based ECPR (Jean-Jacques Laffont, Patrick Rey and Jean Tirole [in the following: L-R-T] 1998a). However, the entry decision may be distorted by using marginal costs.
} 
- it is usually embraced by incumbents, because it seems to transfer the status quo profit margin to the competitive state,

- it does not require a change in (regulated) prices of final services and does not interfere with politically popular cross subsidies (and universal service policies).

The controversies surrounding the ECPR can be traced to its dependence on the incumbent's retail prices. These are taken as given while many economists and regulators view a reduction of those prices and a rebalancing of their structure as a main function of competition in

telecommunications markets. In the most famous case, the ECPR was upheld by the Privy Council in London as the highest court for New Zealand in such matters, but it was later overturned by a new law in that country. The rule manifests itself, however, in the wholesale discounts that competitive local exchange carriers (CLECs) in the US receive on retail services offered by incumbent local exchange carriers (ILECs).

\subsubsection{New versions of the ECPR}

The major controversies about the ECPR in the academic literature (notably, in the Yale J. on Reg. and in the Antitrust Bul.) have somewhat subsided. This is mostly due to the increased rigor introduced into the analysis. The debate in the Yale J. on Reg. and, to some extent, in the Antitrust Bul. has been about concrete examples rather than about economic models. Once models are used, all assumptions have to be revealed and, under the same assumptions, models have to reach the same results. Thus, as a trivial matter, the ECPR can only be welfare-optimal if it yields the same result as a model that explicitly solves for welfare-optimal access charges. This is the Ramsey model, which generally results in access prices that differ from the simple ECPR.

In order for the ECPR and Ramsey prices to be equivalent, the following conditions have to be met (Laffont and Tirole 1994; Alexander Larsen 1995):

- The downstream services of incumbent and entrant(s) are perfect substitutes.

- The entrants have no market power (Bertrand competition downstream).

- The downstream industry produces at constant returns to scale.

- The benchmark pricing rule is marginal cost pricing. 
- There is no bypass in the upstream market.

These conditions could be fulfilled for simple resale of the incumbent's services, while facilities-based providers are likely to offer imperfect substitutes and benefit from scale economies.

If the equivalence conditions are not met, is the ECPR a good approximation of Ramsey prices? It takes a more sophisticated version of opportunity costs for the ECPR to be theoretically attractive in a realistic setting (Armstrong, Doyle and Vickers 1996). The resulting formula is, at the same time, much more demanding on the regulator than the simple ECPR. The opportunity cost then needs to reflect cross elasticities of final demands, technical substitution and types of downstream competition (sophisticated ECPR). Under dominant firm competition, the efficient component price differs from the Ramsey access price by an inverse elasticity term reflecting the effect of the firm's budget constraint (Armstrong 2002). In a dominant firm model the Ramsey price is higher than the efficient component-price because an increase in the access price allows the dominant firm to lower its prices downstream and that simultaneously reduces the productive inefficiency of the competitive fringe. To conclude, done correctly, the sophisticated ECPR is as hard a rule to follow as the Ramsey pricing approach.

The ECPR will, under some types of competition, ex post be satisfied by any equilibrium retail market outcome (of a two-stage game) if access prices are regulated at any level and if retail pricing is left to the market. For example, homogeneous Bertrand competition will always ex post yield the ECPR (in the sense that the access charge will equal the incremental cost of access plus the foregone profit contribution). In such a case the ECPR would appear as an equilibrium result of competition rather than as a starting point of access price setting by an incumbent with market power (Carlos Lapuerta and William Tye 1999). Moving from the conventional static framework to a dynamic analysis of the ECPR in the context of deregulated outputs, Dennis Weisman (2002) shows that a relatively inefficient, but not "grossly inefficient," vertically-integrated provider would end up earning positive profits in equilibrium under marginal cost access pricing, but zero profits under the ECPR in a framework with Cournot 
competition downstream. ${ }^{9}$ The reason is that, in successive periods, the market price would fall because the more efficient rival(s) gain market share over the incumbent. Each time the market price falls so does the ECPR access charge. Thus, Weisman (2002) would suggest that the ECPR only benefits the (mildly inefficient) incumbent at the time of entry, while the incumbent later loses all advantages.

The ECPR requires an adjustment, once entrants have bypass opportunities. In this case, the costs of bypass for an entrant (which could not exceed the stand-alone costs) would provide an upper bound for access charges. Gregory Sidak and Daniel Spulber (1996) call the resulting rule the M-ECPR. Because it is based on a market-adjusted retail price, the sum of retail and access charge revenues are not necessarily compensatory for the incumbent. Sidak and Spulber therefore suggest adding end-user charges on the outputs of rivals as a second policy instrument. While these end-user charges come in as an afterthought, a more systematic approach to bypass would simultaneously derive optimal input price and end-user charge. In a simple model, Armstrong (1999 and 2001) considers the purchase of unbundled network elements (UNEs). ${ }^{10}$ The resulting charge for UNEs should be set at marginal cost (to adjust optimally the quantity purchased), while the tax on rivals' outputs reflects the profit lost by the incumbent. While the tax is levied on the input, it would be paid independent of whether the input was purchased from the incumbent or not. Thus, the tax has no distorting effects on bypass decisions and simply makes sure that only efficient entry occurs. Since the model used is extremely simple, its application to more realistic circumstances needs further analysis, but the principle seems to be quite general.

\footnotetext{
${ }^{9}$ There are two problems with this approach. The first is that the ECPR is a pricing rule that does not easily translate into a quantity framework. The second is that, in equilibrium, the mildly inefficient incumbent does not sell downstream. Then the question arises what its relevant downstream price for the derivation of the efficient component-price is.

${ }^{10}$ The US Telecommunications Act of 1996 requires incumbent local exchange carriers to provide other telecommunications carriers access to individual components of their networks on an unbundled basis. The most important of such elements are the local loops that connect subscribers to the first wire center in the network.
} 


\subsubsection{The relationship between the ECPR and imputation}

Foreclosure incentives resulting from the incumbent's simultaneous pricing in the access market and in the retail markets can be curtailed by requiring imputation. Under the imputation requirement the incumbent may not price access or interconnection at a lower price to itself than to others. While internal prices, in contrast to external transaction prices, do not usually have direct allocative effects (because internal payments cancel each other out), they can be used as an accounting device to discover cross-subsidies. The imputation requirement found in most regulatory jurisdictions shall thus guarantee that the retail stage is not cross subsidized. This is the essence of the Jerry Hausman and Timothy Tardiff (1995) suggestion that the incumbent's retail prices should not be lower than the access charge plus the incremental cost of the downstream stage. If the access charge equals the efficient component price the imputed internal transfer charge cannot be smaller than the retail price minus the (incremental) resource costs of the retail stage, meaning that the internal transfer charge cannot be smaller than the efficient component price. An external access charge exceeding the efficient component price would therefore reveal the retail stage to be cross subsidized.

Imputation makes the incumbent's retail pricing options depend on the level and structure of access charges. Therefore, if the incumbent wants to implement optional pricing (nonlinear tariffs) at retail, it may have to offer nonlinear (discriminatory) access charges (Laffont and Tirole 2000, Section 3.2.3.3). At the same time, as argued below in Section 2.2.5, nonlinear access charges can favor the incumbent over entrants, because the incumbent is its own largest access user.

\subsubsection{Cost-based Prices}

\subsubsection{Rationale and approach}

Besides Ramsey pricing and the ECPR, the third approach in the literature is to base access prices plainly on costs. In the form of first-best marginal-cost-pricing the cost-based approach to public utility pricing was dominant among economists for the better part of the $20^{\text {th }}$ century. It is 
thus not surprising that cost-based pricing resurfaces, as public utilities enter the competition age. Instead of marginal costs, it is incremental costs that have taken center stage now as the basis for access charges in many countries, including the UK, most of the remaining EU and the US. Incremental costs equal marginal costs for small output changes but may differ substantially from marginal costs if they include large output changes up to entire services. The latter, also known as total service incremental cost, is relevant for entry decisions, while marginal cost is relevant for decisions to expand output. In addition, stand-alone costs play an important role. They are the costs of a single-product entrant for providing that single service. Under a costbased approach the average stand-alone costs of a (hypothetical) wholesale network operator would be an upper limit for access prices charged by an integrated incumbent. This holds because prices above stand-alone costs would be unsustainable under (hypothetical) competitive conditions. Usually, the lower limit would be average incremental costs (or short-run marginal costs). Otherwise, the access service would be cross subsidized. ${ }^{11}$ Imposing stand-alone costs as an upper-bound constraint on access charges is adequate, while setting them at stand-alone costs would often be too high. For example, a bottleneck is defined by the fact that duplication of the facility by an entrant would not be economical, meaning precisely that supplying access at the entrant's stand-alone costs of the bottleneck would render him not viable.

\subsubsection{Incremental costs with markups}

As is well known, pricing at incremental costs can only be welfare optimal under specific conditions. In particular, there should be no regulatory incentive problem and the technology should exhibit no economies of scale and scope. Under these assumptions, however, the access problem would be trivial to begin with. There would simply be no bottleneck. So, why have many regulators (for example, in the UK and US) adopted access pricing based on incremental

\footnotetext{
${ }^{11}$ This incremental cost test is a sufficient condition for cross-subsidization in the absence of diseconomies of scope. We are here neglecting the possibility that network access may efficiently be priced below marginal/incremental costs because of network externalities or because of imperfect competition in the retail market, but the issue resurfaces in Section 3 for bill-and-keep arrangements.
} 
costs with limited markups (usually staying below stand-alone costs) $?^{12}$ The various parts of the answer combine to a belief that (Ramsey) efficient access charges would be close to incremental costs of access. The strongest expression of this is contained in Hausman and Tardiff (1995), basing it on the Peter Diamond and James Mirrlees (1971) analysis of optimal taxation, which implies that intermediate inputs should be priced at incremental costs. However, since the incumbent would have joint and common network costs, Hausman and Tardiff suggest a restructuring of retail tariffs such that joint and common costs could be financed by an increase in the monthly subscriber line charge, which would act almost as a lumpsum tax. To the extent that the subscriber line charge can be interpreted as the fixed fee of a multi-part tariff, this also suggests that nonlinear pricing in a noncompetitive downstream market could help solve the access pricing problem.

Other reasons for incremental cost pricing of access include, first, the presumption that economies of scale and scope in the telecommunications industry are no longer very pronounced. Econometric cost estimates are fairly ambivalent on the prevalence of economies of scale and scope in telecommunications networks. ${ }^{13}$ At the same time economies of scale and scope appear to prevail at least in parts of networks. However, service-specific economies of scale can be captured in the average incremental costs of those services. Thus, only true common costs would not relate to service-specific scale. To the extent that economies of scale and scope have vanished bypass would become an efficient alternative to the use of access to the incumbent's network. The second reason is that access and interconnection provide for particularly large network externalities that would justify reduced markups of access prices on costs. The third reason is that markups over marginal/incremental costs for intermediate inputs create inefficiencies through double marginalization. Since entrants have their own overhead and other common costs, they have to charge a markup on top of the access prices they pay. Thus, retail competition itself entails markups and quantity adjustments that reduce the optimal access charge (possibly below incremental cost). The fourth reason is that high access charges could

\footnotetext{
${ }^{12}$ In addition, see Jens Arnbak et al. (1994), Bridger Mitchell et al. (1995), Bridger Mitchell and Ingo Vogelsang (1998).

${ }^{13}$ See, for example, Lewis Perl and Jonathan Falk (1989) or Richard Shin and John Ying (1992). Melvyn Fuss and Leonard Waverman (2002) question the validity of all past cost estimations.
} 
reduce competition by making the integrated supplier a soft competitor downstream (Laffont and Tirole 2000). Fifth, high access charges would invite possibly inefficient bypass investments by entrants. According to Armstrong (2001 and 2002) the importance of bypass opportunities provides the strongest argument for basing access charges on costs. Other policy goals may then have to be achieved with instruments other than access prices.

In spite of all these reasons in favor of incremental cost pricing, markups for common costs will usually be required, which implies that the arguments above do not tell the whole story. In particular, common costs may not be negligible and stranded costs and quality concerns may play a role. Jens Arnbak et al. (1994) and Bridger Mitchell et al. (1995) suggest maximum markups not to exceed the average retail markup applied by the incumbent. Such markups should be additive and not proportional to price, because otherwise the incumbent would have to increase the retail markups to compensate (Laffont and Tirole 2000, Section 4.2). Markups raise revenues and lead to allocative distortions. The resulting tradeoff is heavily influenced by the competitive alternatives. Under easy bypass low markups could be efficient and need not be the result of regulation. If bypass were difficult, higher markups could be sustainable, but they would need to be regulated.

In any case of incremental cost pricing of access the investment effects and competitive implications have to be kept in mind. In principle, access pricing should enable the incumbent to invest efficiently in the bottleneck infrastructure and the entrant to make efficient bypass decisions. At the same time, the charges should be competitively neutral. Since fulfilling several goals may be too much for a single instrument, a tax on downstream sales may be needed for optimal results. Also, the dynamic implications through investment and expansion of rivals may require the derivation of a price path for access charges. Regulated access charges could increase over time, for example, in the market share of rivals (as suggested by Paul De Bijl and Martin Peitz 2003 for two-way interconnection) or in the availability of bypass options (Martin Cave et al. 2001), but downward flexibility could be necessary to prevent inefficient bypass. 


\subsubsection{Exclusionary practices resulting from low access rates}

Cost-based access charges require markups to compensate for fixed and common costs. If these markups are insufficient (and lower than the retail markups), the incumbent faces incentives to deteriorate access quality or to exclude rivals (Laffont and Tirole 2000, Section 4.5). While higher access charges increase opportunities for predation, they reduce the incentive to do so (Gary Biglaiser and Patrick DeGraba 2001). A recent set of papers explicitly deals with the incentive of vertically integrated firms to use nonprice discrimination, called "sabotage," to disadvantage downstream rivals that have to buy an essential upstream input from the incumbent (Weisman 1995, 1998; David Sibley and Dennis Weisman 1998a, b; Nicholas Economides 1998; David Reiffen 1998; Randolph Beard, David Kaserman and John Mayo 1999). The literature on sabotage is discussed and synthesized in David Mandy (2000), who finds that foreclosure depends mainly on three parameters: the access charge markup, the extent of downstream competition and the relative inefficiency of the incumbent in the downstream market (assuming that there are no economies of scope benefiting the incumbent). He identifies combinations of these parameters that would lead to sabotage and combinations that would not. In line with Economides (1998), if sabotage occurs it leads to the foreclosure of all downstream rivals. Applying his results to the Section 271 cases under the 1996 Telecommunications Act, ${ }^{14}$ Mandy finds that the markup provided by regulated interstate access prices is low compared to hypothetical unregulated access prices. Thus, even if RBOCs were quite inefficient in providing long distance and if long-distance markets were quite competitive, RBOCs would still have strong incentives for sabotage. ${ }^{15}$ Since discovery and suppression of sabotage is difficult for a regulator, this suggests that the socially optimal access charge may be higher than in the absence of sabotage possibilities. ${ }^{16}$

Ceteris paribus, higher markups in the access market imply less incentive to raise rivals' costs. Because such incentives can only be suppressed by heavy-handed regulation, Laffont and

\footnotetext{
${ }^{14}$ Section 271 spells out procedures and conditions under which Regional Bell Operating Companies (RBOCs) are allowed to enter long-distance markets in their states.

${ }^{15}$ The sabotage incentive crucially depends on the incumbent's market share downstream (Sibley and Weisman 1998a).

${ }^{16}$ I owe this observation to an anonymous referee.
} 
Tirole (2000, Section 4.5.3) plead for more light-handed regulation that allows the incumbent sufficient flexibility in setting access prices, for example, under global price caps. Within the price caps, an access charge price floor would guarantee profitability of selling access and, if binding, would reduce profitability of downstream services (Ibid., Section 4.8).

\subsubsection{Cost measurement}

Firms have always measured some form of their costs. ${ }^{17}$ The measurement of economic costs of individual services or network components (elements) in telecommunications, however, is a difficult undertaking because of the forward-looking nature of economic costs, because of rapid technical progress and because of economies of scale and scope, resulting from the use of longlived assets.

In the US, cost models are being used to measure universal service costs, costs of access and retail services and costs of individual network elements and of the retail function. Measurement of local network costs was pioneered by Mitchell (1990) and is now done by all large US ILECs (incumbent local exchange carriers). Most of them have their own cost models. While these firm-specific models can, in principle, best reflect local geographic and market conditions, they and their data inputs are less open to outside scrutiny than models developed and run by independent institutions. However, to the extent that firm-specific models are used in regulatory proceedings, they are getting scrutinized by regulators and adverse parties. Rather than accept one of the models proposed in the partisan process as the basis for its universal service policy the FCC constructed its own Hybrid Cost Proxy Model. All of these are so-called proxy models ${ }^{18}$ that, without modifications, can be applied to all regions of the US. Only the data input changes between localities.

\footnotetext{
${ }^{17}$ See, for example, David Gabel and Richard Gabel (1997) for a history of cost measurement in the US telephone industry.

${ }^{18}$ The other cost models were developed on behalf of (a) firms competing with the ILECs (the Hatfield Model), (b) the National Association of Regulatory Utilities Commissioners (the Gabel/Kennet Model, which forms the basis for the German cost models and for the work of Farid Gasmi, Jean-Jacques Laffont, and William Sharkey 1997, 1998) and (c) a mixed industry group (the Benchmark Cost Model and its derivatives).
} 
Cost measurement requires agreement on a number of principal issues, including (1) the appropriate cost category, (2) the valuation and depreciation method, (3) the efficiency of costs and their time horizon, (4) the inclusion of uncertainty in the presence of sunk costs, and (5) the treatment of common costs, takings and access deficit recovery.

The appropriate cost category: The candidates for the appropriate economic cost category are marginal costs, incremental costs, stand-alone costs (and fully allocated costs). US regulators and many others around the Globe have opted for total service longrun incremental costs (TSLRIC). ${ }^{19}$ The main argument in favor of this concept has been that access prices at TSLRIC would provide the right entry or bypass (make-or-buy) decision. The "TSIC" part is justified over marginal costs, since an entry decision concerns a service rather than a unit of service, while the "LR" part is justified by the longrun aspects of entry or bypass. The choice between incremental and stand-alone costs is not straightforward in the presence of economies of scope. In this case, incremental costs on average underestimate total costs, while stand-alone costs on average overestimate total costs. Regulators therefore include a markup above TSLRIC to account for common costs, while scale economies are covered by the total service concept.

Valuation and depreciation method: Once agreement has been reached on the cost category, a valuation and depreciation method has to be chosen. Problems arise here from technical progress and changes in input prices over time. Since economic analysis interprets costs as forwardlooking, the appropriate asset valuation would be at current costs. However, Graham Guthrie, John Small and Julian Wright (2000) show for the downward-drifting asset prices relevant for telecommunications that historic cost valuation could have its merits. Depreciation is tricky, because prices are explicitly based on costs, while economic depreciation would depend on the future returns of the asset and therefore on the resulting prices (Michael Salinger 1998). The resulting simultaneity of cost and price determination should require depreciation schedules only for tax calculations (Mandy 2002).

The efficiency of cost and the time horizon: Cost measurement based on actual data appears to be naturally superior to measurement based on estimated or average data. For that reason

\footnotetext{
${ }^{19}$ Better known to the public is the TELRIC concept, which refers to the costs of network elements (Total Element Long Run Incremental Cost).
} 
actual data are usually made available to the regulator. But the stated superiority of actual data may not hold at all, because the actual data may reflect cost inefficiencies and may distort cost measurement. For example, regulated monopolists in the US may have an incentive to overstate common costs relative to directly attributable costs (Mark Burton, David Kaserman and John Mayo 1997) or costs may actually be inflated under rate-of-return regulation. While an efficient firm standard to access charges would prevent such gaming, an entrant might then always want to buy access rather than build its own network (Alfred Kahn, Timothy Tardiff and Dennis Weisman 1999). Thus, the efficient firm standard would not allow the most efficient (among imperfect firms) to provide the service, whereas the use of the regulated firm's actual costs would make the entrant bypass the incumbent's facilities whenever the incumbent is less efficient. This argument, however, implies the use of short run costs because, in the long run, all costs can be changed so that it is unclear, what actual costs would be. Furthermore, actual (shortrun) forward-looking costs do not include sunk costs. Thus, depending on the fraction of sunk costs, it is unclear if the efficient firm and longrun cost standard leads to higher or lower costs than the actual cost standard. In practice, the FCC has used a compromise approach in TSLRIC modeling by taking the location of nodes as given (scorched node approach) rather than optimizing over the whole network design (scorched earth approach).

The use of actual cost data in regulation (and long-term contracts) is known to provide weak incentive effects. In contrast, because proxy models are built on (price and quantity) data that are not firm specific and location specific, they can function as benchmarks with strong incentive effects. Thus, for regulatory purposes, firm-specific models are not necessarily superior to proxy models.

Uncertainty and the presence of sunk cost: Uncertainty has usually been captured in cost measurement in the form of fill factors for capacity utilization and markups on the risk-free rate of return on assets. A major controversy has, in this context, arisen about the use of real options methods for evaluating the costs of network elements. Jerry Hausman $\left(1997,{ }^{20} 2000\right)$ criticizes the lack of contractual commitment by access seekers under the US Telecommunications Act of 1996 equating it with a free option. The relevant costs of network elements should therefore 
include the options value created by the sunk nature and natural uncertainty of investment. This would be a problem of downside risks created by the fact that the buyers of access do not have the same long-run commitment to the assets as the integrated incumbent. As a result, if demand by the entrants vanishes the assets can get stranded. Hausman calculated very high capital costs resulting from this problem of sunk assets. In contrast, Glenn Hubbard and William Lehr (2000) emphasize the importance of balancing this downside risk by the upside potential. However, such upside potential is only likely to emerge after deregulation and deregulation will only occur if capacities are not scarce.

Common costs, takings and access deficit recovery: Basing access charges on TSLRIC (plus some common cost markup) can hurt the incumbent if it has been unable to use economic depreciation in the past or if it has to price other services, such as consumer access (as opposed to the "access" in "access charges"), below their economic costs. In the presence of these two problems, known as the stranding problem and the access deficit problem, TSLRIC could lead to takings by the regulator (Sidak and Spulber 1996; Laffont and Tirole 2000, Section 4.4.2). The empirical questions here are (a) if the regulators had (implicitly) made any promises about continuing past regulation, (b) if the expected value of the incumbent's profits under the new regime would fall significantly and (c) if compensation for such a burden has been provided elsewhere. In 2002, the US Supreme Court ruled that TSLRIC does not in principle violate the ILECs' constitutional rights. ${ }^{21}$

Since cost measurement is needed for all the access pricing methods discussed so far, the resulting problems will continue to provide fertile grounds for research.

\subsubsection{Access Price Caps and Global Price Caps}

\subsubsection{Rationale}

In practice, all three access pricing rules present large difficulties for implementation. A regulator cannot hope to capture all the competitive and demand-related effects of the Ramsey

\footnotetext{
${ }^{20}$ See also the comments by Gregory Rosston in the same source.
} 
pricing formula at the same time ${ }^{22}$ the sophisticated ECPR is not much more feasible; and costbased access charges are hampered by tedious and contentious cost determinations that always lag behind cost developments. Furthermore, common cost markups are unsystematic and not related to allocative efficiency. Incentive regulation in the form of price caps has been designed to overcome problems such as these. Price caps consist of an adjustment formula ("RPI-X") that is applied to a price cap index of the firm's outputs. The adjustment formula is meant to cut the tie between price and (firm-specific) cost development and thereby to provide incentives for cost reduction. ${ }^{23}$ The use of a price-cap index (baskets) with the right quantity weights shall induce the firm to restructure its prices efficiently and potentially relieves the regulator of the informational burden to establish (Ramsey-) optimal price structures. ${ }^{24}$

\subsubsection{Access price caps}

As a step toward more light-handed regulation, access price caps that were separate from retail price caps were introduced in the US in 1991 and in the UK in 1997. The motivation was that they should prevent exclusionary practices, including squeezing and predatory behavior and, at the same time, provide incentives for efficient access charges.

The problem of exclusionary practices is already reduced by the separation of access price caps from retail prices, because dominant integrated incumbents are thereby prevented from increasing access charges relative to end-user prices. Anticompetitive practices could, in this context, nevertheless arise from the ability of the incumbent to increase some access prices while lowering others, with the aim of disadvantaging competitors. Regulators in the US and UK have therefore restricted access charge rebalancing. There appears to exist no academic literature on this issue, though.

\footnotetext{
${ }^{21}$ The September 2002 issue of the Review of Network Economics is devoted to this topic.

${ }^{22}$ These effects do not yet include cost-reducing incentives as discussed in Laffont and Tirole (1993).

${ }^{23}$ Provided the X-factor is in fact set independently of firm performance. Often this is difficult because of the link between $\mathrm{X}$, investment and quality issues.

${ }^{24}$ This argument goes back to Ingo Vogelsang and Jörg Finsinger (1979). For a survey on price caps, see Michael Crew and Paul Kleindorfer (1996).
} 
If price caps work as designed they should lead to Ramsey optimal prices. However, this would only hold for each price cap basket, viewed in isolation. The possibility of rebalancing access charges within the set of access services can thereby improve efficiency incentives, similar to retail price caps. However, any Ramsey approach that restricts itself to a subset of markets is theoretically inferior to one that includes more markets. The empirical question then is if the beneficial effects from the avoidance of exclusionary practices in such markets can compensate the mistake from not including all markets under a single regulatory constraint.

\subsubsection{Global price caps}

Global price caps differ from separate retail and access price caps in that they include access charges along with retail prices under the same cap (in a single basket). Laffont and Tirole (1994, 1996) have made a strong case for global price caps, arguing that, from the incumbent's perspective, access is a service like others. Making the integrated firm choose its overall price structure under a common constraint on the price level can then align the incentive for optimal pricing in both markets. The asymmetry created by unequal treatment of access charges and enduser prices would vanish under global price caps. The incumbent would use its superior information in a welfare-enhancing way. Laffont and Tirole do, however, assume that the pricecap index uses optimal weights to begin with. In addition, they want to reduce any incentives for anticompetitive behavior by imposing an imputation rule for access pricing in addition to the price caps. Thus, any individual access charges would have to obey both the price cap and the imputation rules. The imputation rule is imposed to alleviate the danger of predation. Although continued price cap regulation would reduce the future prize of predation, such danger cannot be dismissed without further proof. ${ }^{25}$

Optimal weights for the price-cap index would be the correctly predicted output levels. Making such predictions means solving the Ramsey pricing problem discussed above in Section 2.2.1. This would be very hard and would make the use of price caps superfluous because, by

\footnotetext{
${ }^{25}$ For an example of predation under retail price caps only, see Vogelsang (2003).
} 
solving the problem, the regulator could prescribe Ramsey prices directly. Thus, in applying global price caps one will probably have to compromise on weights that are either quantities of past periods or quantities projected from past trends. While chained Laspeyres weights are not fully optimal, they may prevent predatory behavior, because after a price squeeze output price weights would be high and access charge weights would be low. It would therefore take a large access price reduction to permit output price increases in order to recover the costs of predation. Reentry would thereby be facilitated (Ingo Vogelsang 2002, 2003).

Global price caps have so far been too bold for any regulator to implement. One reason is the common knowledge among all participants that regulators cannot commit to a specific regulatory scheme in the long run. Thus, under global price caps, the integrated firm may use aggressive tactics against rivals, in order to keep its overall market position, just in case regulation changes in the future.

\subsubsection{Access prices when retail is deregulated}

Access regulation, which makes the facility available to competitors under regulated terms, could sufficiently lower entry barriers downstream even though the vertically integrated incumbent maintained a dominant market share. Thus, fully deregulated retail prices in connection with regulated access could be an attractive form of light regulation. In this case, the function of access charge regulation would be to enable and improve the competitive outcome. The optimal access price regulation would therefore have to depend on the competitive interaction between incumbent and access seekers downstream.

From an efficiency perspective the main issues of deregulated retail prices are the downstream markup and the productive efficiency of incumbent and rivals. For example, if lumpsum subsidies were feasible an access charge below marginal costs could compensate for downstream markups under Cournot oligopoly. More realistic at least in the early years of competition is the dominant firm model and the absence of subsidies. In the static dominant firm case entrants are always productively inefficient so that increased competition leads to a tradeoff between more productive inefficiency and lower downstream markups. Under perfect 
substitution between the entrant's and incumbent's outputs optimal access price regulation can then lead to an access price above or below marginal cost of access (Mark Armstrong and John Vickers 1998). Output-wise the two distortions go in opposite directions. The access charge is a single instrument to correct both these inefficiencies, leading to a compromise (or second best) outcome. Setting a low access charge leads to more productive inefficiency by the entrant while setting a high access charge leads to too high a downstream markup by the incumbent. Marginal cost pricing of access then turns out to be optimal for linear demands in the heterogeneous demand case (and a nonbinding profit constraint).

Models of Bayesian incentive mechanisms have so far played no role in the policy debate about access charge regulation. ${ }^{26}$ However, asymmetric information between regulators and regulated firms obviously has importance for access pricing. Tracy Lewis and David Sappington (1999) address access price regulation under asymmetric information in the context of heterogeneous downstream competition. Downstream markets are not regulated, while the access market is regulated under a Bayesian scheme. The main normative insight is that the regulator, in setting access charges, should tilt the playing field in the direction of the more efficient downstream firm and that this tilting should decrease in the intensity of downstream competition. This contrasts with the result by Gianni De Fraja (1999) that, in the context of regulated access and downstream prices, the regulator may bias access prices downward in order to favor an inefficient downstream rival. Entry competition here induces the incumbent to exert more costreducing effort.

While nonlinear pricing downstream is widely acknowledged in the access and interconnection pricing literature, nonlinear access prices are hardly discussed. As shown by Henry Ergas and Eric Ralph (1997), a lump sum monthly fee, combined with usage fees, generally improves welfare over using the ECPR in the case of unregulated downstream services. For a large range of parameter values improvements would occur even if the regulator did not prescribe optimal fees. However, a problem with this approach is that the incumbent is usually very large relative to the other competitors. As a result, it can circumvent imputation rules by

\footnotetext{
${ }^{26}$ Bayesian incentive mechanisms incorporate asymmetric information in a principal-agent framework and are fully welfare optimal in that constrained sense. See Laffont and Tirole (1993) for a comprehensive treatment.
} 
designing a nonlinear tariff that provides a particularly low usage charge (combined with a high fixed charge) for itself as the largest user. Thus, the incumbent can argue that it charges itself the same nonlinear tariff as it charges others and nevertheless foreclose them. What the Ergas and Ralph analysis, however, brings out clearly is that simple per-minute charges are usually inefficient because they do not reflect well the cost structure of networks. Nonlinear, peak-load or capacity-based access charges could therefore be substantially more efficient (Ingo Vogelsang and Ralph-Georg Wöhrl 2002).

\subsection{Conclusions on One-way Access}

While the price regulation of one-way access appears to be an indispensable policy instrument for initiating and maintaining competition in telecommunications networks marred by bottleneck facilities, it is a very imperfect instrument. The fewer tasks it is given the better it will likely fulfill them. In particular, access price regulation is directed at an intermediate input and therefore at productive efficiency. It is not the best instrument for correcting downstream distortions at the same time (Armstrong 2002). This would be the task of other, output-related instruments, such as end-user price regulation or universal service policy. In the past, under regulated monopoly or public ownership, telecommunications policy has attempted to do many things. Once competition is introduced, new issues emerge that complicate regulation. If the regulator is then not willing to let go the old policy tasks, such as cross-subsidization in favor of certain user groups, regulation will become much more complicated than before.

Taking Ramsey prices as the efficient but impractical standard, each of its alternatives simplifies or neglects some of its properties. The ECPR takes final goods prices as given. Costbased access charges use proportional rather than differentiated markups. Price caps substitute imperfect incentives for control of markups but, in the case of global price caps, could approximate Ramsey prices. Last, end-user price deregulation would substitute for downstream Ramsey prices and would work well with access price caps. All three principal access-pricing

methods, Ramsey pricing, the ECPR and cost-based pricing have their advantages and drawbacks. Ramsey prices and a theoretically clean ECPR require detailed information about 
demands and competitive interactions in addition to the cost information required for cost-based access charges. Global price caps or access price caps can reduce these information requirements but will only approximate the desired result at best. In principle, the ECPR will provide the best entry signals if downstream prices are optimal and if bottlenecks cannot be bypassed, while cost-based access charges will provide the correct bypass signals for the access facility and will work best if downstream competition is intense or if other policy instruments correct for downstream distortions. Increasing regulated access charges over time in a predetermined way could provide incentives for entrants to build bypass facilities and could well reflect increased downstream competition.

In practice cost-based access charges with small common cost markups have come to prevail worldwide. The ECPR has relevance for resale of services of incumbent local exchange carriers (ILECs) in the US. A major insight from the ECPR is that, in the absence of a second instrument (tax), access charges may have to mimic the incumbent's retail price structure if the regulator imposes a particular retail price structure (such as geographically uniform prices) on the incumbent. However, a second instrument would be preferable for achieving noncompetitive goals, such as universal service. Access price caps are used in the UK and, for long-distance access charges, in the US. "Sabotage" is handled through detailed provisions on access quality. Research on the benefits of this approach over light-handed regulation or higher (marginal) access charges would be desirable. Given the controversies and difficulties in finding acceptable methods of regulating access prices, new approaches are worth looking at. For example, Noam (2001) suggests that the prices for monopolistic bottleneck segments, charged by the incumbent (or any other carrier) be piggy-backed on competitive prices, by setting the price for monopolistic segments equal to the average of competitive segments (adjusted for lower densities, etc.). The implementability of this suggestion would depend on the extent of competitive alternatives that could be used as benchmarks for bottleneck services. 


\section{Two-way Access}

\subsection{Issues: Collusion versus exclusion}

Two-way access has been around for a long time in the form of international calling arrangements between countries (settlements) and the arrangements between adjacent local exchange companies in the US..$^{27}$ These involve carriers that do not compete with each other (what Noam 2002 calls parallel interconnection). In contrast, the two-way access problems we are concerned with occur between competing carriers operating at the same level of integration and offering local and long-distance services. Thus, these firms use each other's bottleneck inputs and compete with each other. The issues arising in this context are collusion and exclusion. While collusion is more of an issue in symmetric interconnection relationships, exclusion is more likely by a large network provider interconnecting with a small network provider.

\subsection{Interconnection pricing models}

\subsubsection{Symmetric competition}

\subsubsection{General modeling assumptions}

In the context of international calls between countries with different monopoly providers, the interconnection pricing problem in the non-cooperative setting burns down to the pricing of two inputs (termination on each side) at their respective monopoly prices. Combined with their retail monopolies this leads to double marginalization and therefore (even in the symmetric case) fails to generate a joint profit maximum. Such a maximum can, however, be easily reached through negotiations, in particular, when reciprocity of the interconnection charge is imposed. In this case, interconnection charges would equal marginal costs of termination. If costs differ side payments may be required or inefficiencies can result under the requirement of reciprocity (Armstrong 2002). In the international (or adjacent) monopoly model cooperation comes out naturally, because the end-user services produced with interconnection are complementary to 
each other. ${ }^{28}$ Explicit cooperation in this case can lead to lower interconnection prices that reduce double marginalization, while independent behavior increases the problem (Michael

Carter and Julian Wright 1994). When firms offer complementary services their collusion is socially desirable. In contrast, if the end-user services are close substitutes and the firms providing mutual interconnection therefore compete with each other we would expect cooperation between them to be potentially harmful. One of the main questions in the literature on two-way access has hence been if interconnection prices can be used as instruments to facilitate such harmful collusion.

Much of the literature on interconnection pricing is ahead of actual market developments by assuming that the relevant markets have reached a competitive state where the distinction between incumbent and entrants vanishes and where downstream deregulation has already been implemented (such as telephony in New Zealand) or is on the horizon (such as electricity in the UK and the US). The pathbreaking work on these markets with more mature competition has been L-R-T $(1998 \mathrm{a}, \mathrm{b})^{29}$, which has shown enough versatility to form the basis for work on asymmetric market structures.

Although competition is least advanced there, most models might best fit local services in the telecommunications industry. Typically, there are two competing firms that own networks and supply individual consumers who each subscribe to only one network (following from a discrete choice model). Thus, consumers consecutively have to decide on the network they subscribe to and how much to call. If consumers want to communicate with someone on the other network interconnection between the networks is required. Although they could play a major role in such networks, the characteristic telephone network externalities and call externalities (based on incoming calls) are not part of the basic models. Rather, consumer utility only depends on outgoing calls. This has the advantage that any "network externalities" discovered are more easily identified as being of a different kind. Based on L-R-T (1998a, b) common additional consumer-related assumptions of this literature include

\footnotetext{
${ }^{27}$ In the US, this has often led to pooling arrangements. See Dale Lehman and Dennis Weisman (1996).

${ }^{28}$ Substitutability between incoming and outgoing calls would interfere with this model, but does not seem to hold empirically. See Jan Acton and Ingo Vogelsang (1992).

${ }^{29}$ See also Laffont and Tirole (2000), where these articles are explained in more intuitive ways.
} 
- that networks are differentiated in a Hotelling framework, meaning that consumer preferences are spread along a line and networks make product differentiation choices by locating at a point on the line. ${ }^{30}$ In this case, they are assumed to be located at the opposite extreme points of the line. The degree of substitutability between networks is given by the size of transport costs on the line.

- that there are isotropic calling patterns, meaning that, at the same calling charge, the inbound and outbound calls are balanced.

- that consumers subscribe to one and only one network. The total number of subscribers is therefore fixed.

Cost structures of full coverage networks are assumed to be the same. Except for subscriberspecific fixed costs, L-R-T assume no network size related or density related production economies, while De Bijl and Peitz (2003) model an additional firm-specific fixed cost of building a network. Simulations indicate that this does not change the qualitative outcomes. The two L-R-T papers assume unregulated retail markets, while the access market may or may not be regulated. In contrast, Carter and Wright (1999a) and De Bijl and Peitz (2003) also consider regulated end-user markets.

\subsubsection{Linear pricing downstream}

The legal requirement of reciprocity of two-way interconnection charges under the US Telecommunications Act of 1996 has become a common assumption to characterize the symmetric case. The benchmark Ramsey-pricing solution has the access charge below marginal costs, because, due to imperfect retail competition, firms have positive markups in the retail market (L-R-T 1998a). This result is unambiguous because of assumed constant returns to scale. Under economies of scale, Ramsey access charges could be below or above marginal costs, depending on the degree of scale economies and the size of the retail markup.

\footnotetext{
${ }^{30}$ Hotelling product differentiation does not capture perceived quality differences (incumbency advantages) that hold for essentially all consumers. Although the Hotelling model may not ideally characterize product differentiation in telecommunications, it so far is the only game in town for the main results on collusion, which
} 
Ramsey pricing contrasts with competitive interconnection pricing equilibria, which depend on the interconnection price and the degree of substitution between the networks as the main determining parameters. In particular, the existence of a (pure strategy) equilibrium requires the interconnection price and/or the substitutability between networks not to be too high. If substitutability and the interconnection price are high Bertrand competition induces each firm to undercut the others' retail prices in order to avoid having to pay access to the other. In equilibrium, retail prices are symmetric and increase with the access price. The equilibrium retail price decreases with the substitutability between networks and converges against the Ramsey price (if, at the same time, the access price is low enough to allow for existence of the equilibrium). This is a typical result of the Bertrand pricing assumption. Even though traffic is balanced and therefore no net payments are being made, the firms can use access charges collusively to achieve maximal profits.

The last important result was independently derived by Armstrong (1998a). To understand it, consider the effects of access charges above marginal costs. First, the access charge above marginal costs raises each firm's marginal costs for outgoing calls, thus increasing the optimal resale price. Thus, isotropic (balanced) calling patterns do not imply an indifference to the size of the (reciprocal) access charges. The reason is that the balanced outcome is an equilibrium, but would not result if retail prices differed. Second, lowering the retail price has two effects: It lures away subscribers from the other network; and it increases the call volume of given subscribers. Lowering the retail price therefore has a negative effect on access profits. Another way of seeing this is that, at an access charge above the marginal cost of access, the marginal cost faced by a firm for an outgoing call increases in the other firm's market share. This “endogenous marginal cost effect" is due to the increased share of off-net calls. It further lessens the incentive to compete at retail. In Armstrong's (1998a) interpretation, when access charges are set according to the collusive equilibrium rule, then firms have no incentive to deviate from the collusive retail price because the gain in profits from undercutting the rival is just compensated by the increase in access payments needed for the increased number of calls going to the other network (and the

include L-R-T (1998a), Armstrong (1998a), Carter and Wright (1999a) and De Bijl and Peitz (2003), who all use very similar demand frameworks. 
reduced number coming from there). The ability to collude is maintained if brand loyalty leads to different sized networks (Carter and Wright 1999a). Also, even if a regulator imposes marginal cost pricing at retail but regulates access charges only by requiring reciprocity, the networks can sustain monopoly profits by agreeing on high access charges (that increase marginal costs for each other). Thus, negotiation over access charges leads to collusion that would be forbidden in the retail market. As a consequence, Carter and Wright recommend regulation of access charges rather than regulation of retail prices. However, in the absence of regulation the collusive outcome is desirable to the extent that it eliminates the double marginalization that characterizes the noncooperative approach, while it is undesirable because of the monopoly pricing outcome.

Potential nonexistence of equilibria could interfere both with the collusive outcome and with Ramsey pricing. If substitutability is sufficiently high the collusive equilibrium will have to be close to the Ramsey optimum. The joint profit maximum therefore has to produce close to zero profits. That, however, would be a very special case. The collusive result therefore could have practical relevance only as long as the two services are sufficiently heterogeneous. Since, under economies of scale, the Ramsey access price could exceed marginal costs, it could occur in a range, where no equilibrium exists. In such a case, the Ramsey optimum could only be achieved under regulation. The problem with nonexistence of equilibria is that one cannot learn from the model, what actually will happen. L-R-T (1998a) suggest an unstable situation. It does not become clear, however, how severe and common such nonexistence would be. At the beginning of competition in telecommunications markets, close substitutability would be precluded by the goodwill advantage of the incumbent over entrants. However, the history of US long-distance competition shows that this advantage can disappear and then the service can become quite a homogeneous commodity. Nevertheless, the services subject to two-way interconnection are likely to differ by physical properties beyond goodwill so that the non-existence of equilibria may never become a problem. It may, however, be worth looking at the potential relevance of capacity constraints in markets with high substitutability.

In the case of nonreciprocal access charges L-R-T (1998a) apply a two-stage game approach in which both access charges and retail prices are determined noncooperatively. In the 
noncooperative framework the access charges in both directions are independent of each other. They therefore do not act as a coordinating device. ${ }^{31}$ If substitutability is sufficiently low there exists a symmetric equilibrium in access charges and retail prices, involving double marginalization. Thus, reciprocal access charges are an equilibrium outcome in this model. The resulting double marginalization problem is the more severe, the less substitutable the networks are for each other. As long as the equilibrium exists, higher substitutability implies a lower equilibrium retail price, while the effect of higher substitutability on the equilibrium access price is ambiguous.

In contrast to L-R-T (1998a), Nicholas Economides, Guiseppe Lopomo and Glenn Woroch (1996) assume that consumers first choose, which network to subscribe to. Then networks set their prices and then subscribers make their consumption decision. While this sequence seems to reflect the reality that subscription decisions are more long term than usage decisions, it has the unrealistic implication that networks become monopolists with respect to the usage decision of subscribers. As a result, there will always be monopoly pricing for usage. However, if access charges (for termination of calls) are determined unilaterally there will, in addition, be a double markup problem, which vanishes if reciprocity is imposed as a regulatory rule. In a similar vein first-mover advantages disappear under reciprocity. ${ }^{32}$ The conclusion of reciprocal access charges at cost and retail usage charges with a monopoly markup contrasts with L-R-T's (1998a) and Armstrong 's (1998a) reciprocal access charges with a monopoly markup and retail usage charges at (perceived) marginal costs.

\subsubsection{Nonlinear pricing downstream}

The dominant view among economists is that almost no linear pricing exists in telecommunications retail markets for which interconnection is relevant. It is quite obvious that

\footnotetext{
${ }^{31}$ Because this is a one shot game, the authors do not ask if collusion could arise in a repeated game framework.

${ }^{32}$ In spite of the reciprocity requirement the authors use a noncooperative framework. The converse treatment of nonreciprocal access charges in a cooperative framework has been worked out by Carter and Wright (1999b). Reciprocal access charges are an equilibrium outcome, provided the cost and demand conditions are symmetric, while truly nonreciprocal access charges could result if, for example, termination costs differed between the networks.
} 
two-part tariffs and multi-part tariffs abound. ${ }^{33}$ This makes it particularly interesting that, in the L-R-T (1998a) framework, retail competition in nonlinear pricing between two full coverage networks yields interconnection pricing results very different from linear pricing. Since there is only one type of consumer, two-part tariffs can achieve optimum (that is, perfectly discriminating) outcomes under the reciprocity requirement. Because potential customers subscribe to exactly one network welfare-optimal two-part tariffs only require optimal usage fees (for end-users) equaling firm specific marginal costs (that include access charges) and optimal fixed fees equaling marginal costs of adding a customer (net of the net access charge revenue generated) plus a markup reflecting substitutability. Most important, the profit in equilibrium is independent of the access charge. Thus, the access charge creates no incentive to collude and can be set at the efficient level, equaling marginal costs.

The last result comes about because each firm uses the fixed fee to take away subscribers from the other network, while the usage fee stays constant to balance calls between the networks. Thus, both firms use the two parts of the retail tariffs as distinct instruments, one to influence market share and the other to influence calling volume. The strikingly different results on collusive outcomes between the linear and nonlinear pricing cases would be particularly important because nonlinear pricing seems to be the rule rather than the exception in telecommunications.

The assumption of homogeneous subscribers is responsible for the clarity of the two-part tariff outcome. Had subscribers been heterogeneous, usage prices would optimally depart from marginal costs. According to Armstrong (1998a), the collusive impact of high access charges would therefore not be fully eliminated. Wouter Dessein (1998, 2001) and Jong-Hee Hahn (1999) deal with this issue more specifically. Dessein (1998) assumes that there are high volume customers with more outgoing than incoming calls and low volume customers with more incoming than outgoing calls (at the same prices). The high volume customers have a higher price elasticity than the low volume customers. As a result, under linear retail prices an access charge above marginal costs has an even larger collusive effect than in the L-R-T model. At the

\footnotetext{
${ }^{33}$ If having a telephone line were viewed as a service it would not be clear that the monthly fee is the fixed part of a two-part tariff rather than a product price under linear multi-product pricing.
} 
same time, large users are attractive as subscribers, so that competition for them is increased. LR-T's noncollusive outcome under two-part tariffs (and other non-linear prices), however, is confirmed in this setting as it is under a continuous distribution of subscriber demands (Hahn 1999). The reason is that market share competition occurs through fixed fees and has no effect on usage.

The profit neutrality of variable access charges, however, fails remarkably if demand heterogeneity affects the subscription decision and if a network externality enters the demand framework. In this case low reciprocal access charges below marginal cost of termination act as a collusion device for high subscription fees (Dessein 2001). ${ }^{34}$ Low access charges then imply low usage prices at retail, which - via the network externality - make subscription more attractive. In contrast, welfare-optimal interconnection charges tend to be above marginal costs. Since network externalities can be a strong feature of telecommunications sectors, especially at low rates of penetration, Dessein's finding could be empirically important.

Investment effects are a very recent feature of interconnection models. Extending the L-R-T framework by introducing quality-improving investment before the price competition stage, Tommaso Valletti and Carlo Cambini (2002) show that, in spite of two-part tariffs downstream, collusive underinvestment in quality is triggered by negotiated reciprocal interconnection charges, because higher than the rival's quality generates more outgoing calls and therefore an interconnection charge deficit. In contrast, socially optimal interconnection charges would be below marginal costs of termination.

\subsubsection{Bill-and-keep and the value of incoming calls}

In the past, the interconnection arrangements between Internet Service Providers (ISPs) were of the bill-and-keep kind, meaning that reciprocal access services were provided free of charge. These so-called "peering arrangements" have induced some economists, such as Gerald Brock (1995), to call for similar arrangements among competing telecommunications network providers (ILECs and CLECs in particular). More recently, the Internet arrangements have

\footnotetext{
${ }^{34}$ This bears similarity with a result by Joshua Gans and Stephen King (2001) described in Section 3.2.4.
} 
changed. Now, peering without charge only continues between core ISPs, while non-core ISPs have to pay. Using a non-cooperative bargaining framework to analyze the negotiations between a core ISP and other ISPs, Paul Milgrom, Bridger Mitchell and Padmanabhan Srinagesh (2000) hypothesize that in early stages of the Internet network size did not convey a major bargaining advantage so that bill-and-keep arrangements would be likely outcomes independent of relative sizes. In contrast, in the later stage, with increasing market penetration the larger ISPs gain a bargaining advantage over smaller ones because their own customers value outside communications less highly than before. The resulting peering arrangements (and the lack thereof) are efficient, as long as there are sufficiently many core ISPs.

The justification for bill-and-keep interconnection pricing in telecommunications has traditionally included the savings of transaction and measurement cost and the failure of perminute rates to reflect the truly relevant capacity costs of networks (which are zero most of the time and quite high during peak periods). In particular, if these reasons had some importance and if traffic were symmetric bill-and-keep would be a desirable approach for the pricing of telecommunications interconnection. ${ }^{35}$ By now, however, the value of calls to the receiving party and the ability of the receiving network to charge its subscribers for the resulting utility increase has become a potentially much more powerful justification of bill-and-keep, even under asymmetric traffic. This reason had been neglected in the literature, until recent practice in the US showed that entrants could turn the seeming disadvantage of high interconnection charges into an advantage by concentrating on subscribers with more incoming than outgoing calls. If both the caller and the receiver benefit from a call they should both contribute to its payment (DeGraba 2000a; Benjamin Hermalin and Michael Katz 2001). Hence, each network can cover the termination cost it incurs through a call from another network by charging its own subscriber, who has been the called party. ${ }^{36}$ This can take the form of usage charges, as for wireless calls in the US, or additional fixed monthly fees. While the ability of the receiving network to estimate receiver demand for incoming calls could be limited, competition for subscribers could lead to

\footnotetext{
${ }^{35}$ Generally, symmetric traffic will arise independently of the relative sizes of the networks if the characteristics of the subscribers are the same on each network.
} 
efficient prices for incoming calls. In contrast, as argued in Section 3.3, networks usually have a monopoly position with respect to call termination, resulting in distorted pricing under caller pays principles.

Unfortunately, there do not seem to exist demand estimates for incoming calls. ${ }^{37}$ But since we regularly answer the phone, the value is obviously positive on average. Nevertheless, values in both directions are unlikely to be equal (on average). Retail prices to caller and receiver should therefore depend on the two demands and on the sum of originating and terminating costs, but not on their cost share. However, the welfare-maximizing interconnection charges depend on each network's costs, because they influence retail prices (Hermalin and Katz 2001). So, from a valuation perspective, bill-and-keep would not necessarily be efficient but neither would any of the other pricing approaches discussed so far. Compared to those, bill-and-keep may have an important disadvantage, known as the "hot potato" problem, meaning that a network provider will try to hand over a call to the other network as quickly as possible and thereby save on network expansion. In order to avoid this kind of free-riding on other networks and to induce optimal network investment, DeGraba's (2000b) COBAK (central office bill-and-keep) proposal restricts the bill-and-keep portion of a call to the termination of calls from the last central office to the called party, while the sending network would be responsible for transport and switching until that point. ${ }^{38}$ This suggestion also addresses the conjecture that incoming calls are, on average, valued less than outgoing calls (DeGraba 2002).

A major issue with the value of incoming calls is that usually the calling party pays for the call, resulting in a call externality from being called, which is hard to internalize by the two parties. Switching to a receiver-pays regime would eliminate that externality but replace it with a call externality for the caller. Thus, a payment by both parties would be required for eliminating

\footnotetext{
${ }^{36}$ This possibility does not exist for pure wholesale networks that do not have subscribing endusers. Such networks would, under bill-and-keep, have to be compensated based on incremental subscription fees collected by its retail partners.

${ }^{37}$ Given the importance of this subject, such estimates are dearly needed. They could either be derived from experience with the receiver pays principle or as a residual between the demand for outgoing calls and the demand for subscriptions.

${ }^{38}$ In a related approach, Jay Atkinson and Christopher Barnekov (2000) suggest a "default bill and keep solution," under which the networks equally share the costs that are incremental to interconnection and recover their cost share and all remaining costs from their own subscribers.
} 
that externality. In this case the receiver payment would be associated with a discount on termination charges (Doh-Shin Jeon, Jean-Jacques Laffont and Jean Tirole 2001, in the context of two-part tariffs downstream). ${ }^{39}$ By providing network providers with an incentive to institute such a reception payment bill-and-keep is likely to reduce call externalities (DeGraba 2002).

Thus, bill-and-keep, as amended by the COBAK proposal, has a number of advantages over other pricing rules. In contrast, as spelled out below in Sections 3.2.3 and 3.2.4, Dessein (2001) and Joshua Gans and Stephen King (2001) show that, under certain circumstances, bill-and-keep will soften downstream competition.

\subsubsection{Asymmetries between carriers}

Much more realistic than the symmetric case discussed so far are asymmetries in costs between the networks, different market shares and different coverage. Asymmetries in costs should lead to non-reciprocal access prices, both from the welfare and the market equilibrium perspective. John Haring and Jeffrey Rohlfs (1997) treat this first kind of asymmetries by considering costs of incumbent ILECs and entrants (CLECs). The underlying reasons for cost differences between the two are (a) sunk costs that are bygones for the incumbent but need to be spent by the entrant and (b) the greater depth of the ILEC network compared to that of the CLEC. A CLEC will then provide less termination services to an ILEC than the ILEC provides the CLEC.

Haring and Rohlfs suggest an approach to competition in local telecommunications that would be substantially less regulatory than the current US policy. They suggest that the ILECs get flexibility in their retail pricing and be allowed to price interconnection and unbundled network elements at will, with the provision that interconnection prices are reciprocal. This suggestion (attributed by the authors to C.S. Monson) comes somewhat as a surprise after their cost analysis indicates that for most types of unbundled services the ILEC's costs are quite

\footnotetext{
${ }^{39}$ In contrast, Jeong-Yoo Kim and Yoonsung Lim (2001) show in the case of linear pricing downstream that equilibrium reciprocal access charges would be larger than under the calling party pays principle if both, the receiving and the calling parties pay the calling party's network for a call.
} 
different from those of the CLEC. However, by selecting subscribers based on their valuations for incoming calls, CLECs have large influence on the direction of traffic. Therefore, if ILECs set reciprocal interconnection charges too high, CLECs would induce ILECs to incur an access charge deficit. This argument is obviously informed by the observation that CLECs in the US in fact have accumulated large access surpluses with ILECs.

Letting the larger firm choose the interconnection charge but impose reciprocity is formally shown to be optimal by Carter and Wright (Forthcoming) in a noncooperative model similar to L-R-T (1998a), but with a goodwill advantage for one of the networks. In the case of two-part tariffs downstream, the larger network provider will choose access charges equal to marginal costs of call termination. At a higher price, the smaller provider will use a high usage price to end-users to make the dominant carrier incur an access deficit, while at a lower price, the small carrier will charge a low usage price and incur an access deficit. ${ }^{40}$ In both cases, interconnection would become a profitable service for the smaller firm and a loss maker for the larger firm. This is all that matters, since, under two-part tariffs, access charges only affect interconnection profits and not end-user profits. If termination costs differ between networks, the suggestion no longer achieves the optimal outcome (Carter and Wright, forthcoming). In order to take care of this problem, Haring and Rohlfs suggest termination charges that would vary with the location of the point of interconnection in the network, which is similar to "reciprocity in markups" suggested by Economides, Lopomo and Woroch (1996) for interconnection charges in the case of asymmetric termination costs.

Another type of asymmetry involves the situation of an incumbent firm with full coverage and an entrant, who can choose its coverage level. The incumbent's overall market share is now the average between its monopoly in the area not covered by the entrant and its market share in the remaining, competitive (that is, duopoly) area. Under reciprocal access prices mandated to be close to marginal costs the entrant would undercut the incumbent in the retail price and incur an access charge deficit, while it underinvests in coverage in order to soften price competition (entrant as puppy dog). In contrast, under access price determination through bargaining, the 
incumbent may use the access price (or the bargaining process) to corner the market and maintain a monopoly, while the entrant may overinvest in coverage in order to keep the access price down (L-R-T 1998a).

The rationale for these results comes directly from the assumed inability of the incumbent to discriminate geographically by charging a lower price in the duopoly area than in the monopoly area. The aggressiveness of the incumbent's pricing behavior is therefore linked to the size of the entrant's coverage. If the entrant covers only a small territory, the incumbent is pricing less aggressively than if the entrant's territory is large, because the incumbent would like to exploit its monopoly position in its captive area. Hence, the entrant's market share in the duopoly area is going to be larger if that area is small than if it is large.

The entrant's strategy very much depends on the rules for determining price and conditions of access (call termination). Because the entrant prices more aggressively than the incumbent, the entrant wants low termination charges. At the same time, the entrant may also want to use the termination charge as a collusive device. These incentives combine with the default rule on access in case negotiations fail. If the default rule is "no interconnection" the entrant has incentives to invest in high coverage so that the incumbent would be more interested in interconnection. If the default rule is guaranteed interconnection at a maximum price the entrant will underinvest in coverage, in order to soften the incumbent's retail pricing behavior. If expanded coverage by the entrant is a credible possibility, the incumbent may therefore actually prefer mandated, low price access to a default rule of no access or high priced access.

In a related approach, Armstrong (1998a) considers a large incumbent and a small entrant, using the assumption that consumers prefer the incumbent over the entrant so that, at the same retail prices, the entrant's market share would vanish. It is then clear that the entrant can only survive at lower prices. This implies (with isotropic calling patterns) that the entrant incurs an access charge deficit with the incumbent. As a result, the entrant will prefer lower access charges than the incumbent. In this case the access-pricing problem is similar to that of one-way access, interpreting the entrant's demand for access as its net demand (or access charge deficit).

\footnotetext{
${ }^{40}$ Valletti and Cambini (2002) get results in the opposite direction because, in their model, quality-increasing investments increase outgoing call volumes. The larger network (with higher quality) will therefore prefer a smaller
} 
Demand heterogeneity and nonlinear pricing downstream can combine to work in favor of entrants. Under linear pricing, the incumbent can exclude the entrant and enjoy monopoly profit. Under nonlinear pricing, the entrant can avoid such fate by specializing on target groups with special calling patterns and offering them low fixed charges and high usage charges, thus creating an access charge surplus with the incumbent (Dessein 2001).

The dynamic aspects of market entry and the relationship between incumbent and entrant over time are obviously important for an assessment of interconnection regimes. In order to make this manageable in various kinds of market environments, De Bijl and Peitz (2003) resort to multi-period duopoly models, based on myopic profit maximization of incumbent and entrant. The models trace prices, quantities, profits, market shares and welfare levels over time. They assume that entry causes tradeoffs between the presence of consumer switching cost, goodwill advantages and network-specific fixed costs favoring the incumbent and product differentiation advantages favoring the entrant. Thus, entry is beneficial only if the product differentiation advantages are substantial and/or if the entrant is more efficient in costing and/or pricing. Using simulation models over many time periods, De Bijl and Peitz find that optimal access charge regulation often changes, as the entrant gains market share, suggesting an infant industry approach to access regulation.

The regulator can use asymmetric access pricing as a competitive tool. In this case, modeled by Peitz (2002) the access charges to be paid by the entrant for call termination by the incumbent are set at marginal costs, while the incumbent has to pay access charges with a markup on marginal costs to the entrant. This will facilitate entry and, at the same time, improve consumer welfare relative to symmetric markups. This holds for various types of retail pricing, including linear prices, two-part tariffs, flat fees and price discrimination. An interesting feature of asymmetric access charge markups is that the entrant may price subscription and usage for subscribers below costs and compensate the resulting losses by access charges from incoming calls. In simulations run by De Bijl and Peitz (2003) this increases consumer surplus and social surplus in infant competition, while it distorts the market outcome once the entrant has reached sufficient market share. The authors, however, warn that asymmetric access pricing may attract 
inefficient entrants, suggesting that the results might change if entrants had higher costs than the incumbent.

\subsubsection{Discriminatory pricing between on-net and off-net calls}

Originally introduced as "Friends and Family" by MCI in the 1980s, discrimination between calls that terminate within the call originating network (on-network calls) and those that terminate on the other network (off-network calls) has been common in the US telephone industry. In a symmetric market equilibrium the on-net retail price decreases with substitutability and with the access price. If substitutability is sufficiently small, the off-net price increases in the access charge. The main insight of L-R-T (1998b) in this context is to show the existence and working of price-induced network externalities. Belonging to a larger network allows a consumer to do more lower priced on-network calls. Thus, a high access charge that leads to a high off-network retail price hurts a network with a small market share. A full coverage incumbent can squeeze a small coverage entrant through a high access price. This is important for access charge regulation and for regulatory permission of price discrimination in the retail market.

In this discriminatory pricing environment, an increase in access charge may actually increase retail competition, because an access charge increase drives a wedge between the marginal cost of an off-net call as opposed to an on-net call. High access charges therefore are not necessarily a good collusion device. Rather they induce firms to increase their market shares in order to have more on-network calls (avoiding the access charge). In a second best sense, therefore, the price discrimination can improve welfare by reducing double markups (on access and retail) if networks are sufficiently differentiated. ${ }^{41}$ This will happen, because the high off-net price will not have many users. The problem is that, at the same time, the incumbent could foreclose a small entrant. This problem suggests that a regulator would want to forbid such price discrimination (by the incumbent), when competition is in its infancy, while such price

\footnotetext{
${ }^{41}$ Note that price discrimination of this kind has no value in the benchmark Ramsey optimum, because it leads to different marginal rates of substitution between on-net and off-net calls.
} 
discrimination would be advisable, once entrants are viable (having large coverage sunk networks).

Under two-part tariffs and price discrimination downstream, the networks may actually reduce each other's access charges below marginal costs. Bill-and-keep or even negative access charges could then act as collusion devices. This result by Gans and King (2001) turns the "Friends and Family" idea of discrimination between on-net and off-net calls on its head, because access charges below marginal costs would lead to on-net usage prices above off-net prices. ${ }^{42}$ In this case, subscribers will want to belong to the smaller network. This softens competition for subscribers. Thus, end-users are faced with low usage prices and high subscription fees. It is not clear that this specific behavior has any empirical relevance so far, since subsidized subscription fees have been common worldwide. However, it adds to the anticompetitive effects that discrimination between on-net and off-net calls can have.

Overall, the literature shows that discrimination between on-net and off-net calls seems to have few desirable and many detrimental effects, largely because it increases the market power of the dominant incumbent. Disallowing it or restricting it to entrants may therefore be a better policy than a regulated interconnection charge tailored to it. In contrast, DeGraba (2000b) argues that bill-and-keep will by itself reduce the on-net/off-net discrimination issue.

\subsubsection{Conclusions on the interconnection pricing models}

A major difference between optimal pricing under one-way and two-way access is that oneway access charges will not ordinarily be below incremental costs, because the incumbent cannot make up the difference downstream. In contrast, this matters less under symmetric two-way access, because the low access charges are both paid and received. Thus, in the symmetric case, two-way access charges have allocative but no direct budgetary effects. While interconnection prices above marginal costs could be socially optimal, regulated prices discussed in practice have been based on TSLRIC or bill-and-keep. Reciprocity is required in the US.

\footnotetext{
42 Jeon, Laffont and Tirole (2001) show that a connectivity breakdown can occur if receivers value incoming calls and therefore off-net charges are set so that all calls are on-net.
} 
Voluntary agreements on interconnection charges provide a benchmark for the usefulness of regulation. The L-R-T (1998a) and Armstrong (1998) result that reciprocal access charges may be perfect tools for collusion has caught a lot of attention because it would add to collusive tendencies arising from the mere fact that competitors intensely cooperate on an important matter on an ongoing basis. It is therefore reassuring that several features counterbalance the collusive effects. First, collusion would only occur under mature competition with sufficient heterogeneity between the network services. High substitutability would prevent sustainable collusive equilibria, so that regulatory intervention could be required to attain an equilibrium. Second, the use of two-part tariffs at retail could lead to access charges that would sustain welfare optimal usage charges downstream. However, two-part interconnection charges could reinstate the collusive outcome (Carter and Wright, forthcoming), something worth further research. Third, superior coverage or discrimination between on-net and off-net calls can induce the larger network operator to use interconnection for a price squeeze. Fourth, the collusion incentive could be reduced if firms subsidized their subscribers for incoming calls (Laffont and Tirole 2000). The intuition here is that firms would want to do that if access charges exceeded marginal costs, making calls coming from the other network profitable.

The rationale for the last three mechanisms for reducing collusion is that they introduce a second price as an instrument that undermines collusion. The assumption that total subscribership is fixed and independent of prices means that fixed fees can only influence the distribution of subscribers between suppliers but not the total market size (Armstrong 2002). However, under price-responsive subscription demand, the fixed fee would interact with usage and would thus not be a second, independent policy instrument. Furthermore, these mechanisms all work imperfectly, because firms are not fully informed about heterogeneous customer demands.

Given that the collusive effects of requiring reciprocity are in doubt, it is worth emphasizing reciprocity's other properties. Requiring reciprocity in a more realistic asymmetric and noncooperative (Stackelberg) setting could force the incumbent to set efficient interconnection rates, provided downstream prices are deregulated (Haring and Rohlfs 1997; Carter and Wright 
forthcoming). This suggestion is worth further analysis in realistic cases with differing costs and with some downstream regulation.

In the US, CLECs were initially afraid that they would have much more outgoing than incoming traffic (due to multiple lines of business customers, who would use the CLECs for their outgoing traffic, but keep their ILEC lines for incoming traffic). However, the actual calling patterns were often reversed. These experiences suggest that balanced calling patterns are unrealistic and that competitors can target selected customer groups. This can be due to subscriber heterogeneity and/or the value of incoming calls. Including the value of incoming calls has recently started to impact the interconnection pricing philosophy. The insight that each network can charge its subscribers through fixed or usage fees for the value of incoming calls has completely changed the assessment of low interconnection charges or even bill-and-keep, along with the accompanying retail pricing methods and price structures.

What recommendations can regulators take from the literature on two-way access pricing? The literature suggests differentiated approaches depending on symmetries between incumbent and entrant, customer heterogeneity, downstream pricing (and price regulation) and the valuation of incoming calls. Such differentiation in policy could itself have adverse selection and moral hazard effects known as regulatory arbitrage because most of these variables are endogenous. The question then is if there exist either robust specific policies or general policies with sufficiently good properties. In a fully regulated state, COBAK could be such a winning policy if there were only one to choose from. In a large move toward deregulation, including full deregulation of end-user markets, requiring reciprocity seems to be a good policy under many scenarios. In the symmetric case there would be some chance that it leads to a collusive outcome but even that is much preferable over double markups. Since costs are likely to differ between networks, reciprocity is best interpreted as symmetry of markups on termination costs. It contrasts with a policy of asymmetric interconnection charges with initially higher markups for termination on the smaller network than on the larger network and with the difference in markups vanishing over time. 


\subsection{Competitive bottlenecks}

Armstrong $(1998 \mathrm{~b}, 2002)$ terms the problem of monopoly over call termination one of competitive bottlenecks because it can happen under full competition between networks for subscribers. Because the receiving network (usually) has a monopoly for termination to the subscriber being called, it can charge a monopoly price for termination. If callers only have average information about termination charges and do not know which network the receiver subscribes to the termination charges in small networks may even exceed monopoly prices. Free entry can lead to biases in favor of small firms and a dissipation of the resulting monopoly rents in the form of low monthly fees or free phones or the like (Julian Wright 2002b).

Because it only considers high-income economies with mature telephone markets most of this literature totally ignores network externalities. Wright (2002a), however, argues that network externalities still play a role, for example, for wireless networks. He thereby justifies high termination charges on wireless networks that would, under competition between wireless carriers and under the assumption that most calls to wireless customers originate in fixed networks, lead to a reduction of wireless subscription fees and would thereby increase wireless penetration. This, however, has to be weighed against possible reductions in fixed telephone penetration and, more importantly, in usage (DeGraba 2002).

The problem caused by the monopoly over call termination could be substantially reduced by a simple institutional device that was discarded by the US Supreme Court in 1931 in the decision Smith v. Illinois Bell. At the time, the court had to decide if a long-distance company's use of the local network for a call starts and ends at the phones of the calling and called party (station-tostation method) or at the long-distance company's points-of-presence, where interconnection with the local companies occurs (board-to-board method). The court decided in favor of the station-to-station method, making the long-distance company pay for the use of the local network. A victory of the board-to-board method would have resulted in an arrangement similar to bill-and-keep and would have left the call receivers with the payment of termination as local calls. This differs from the COBAK suggestion by DeGraba (2000b) because it additionally burdens the receiver of the call with transport and switching from the caller's carrier's point of presence to the receiver's central office. The tradeoff here is between the potential remaining call 
externalities involved for the caller or receiver and the transaction costs of billing the receiver versus the calling party's carrier with transport and switching until the receiver's central office.

\subsection{One-way and two-way access combined: Unbundled network elements (UNEs)}

In one-way access problems high access charges exclude competitors, while in two-way access problems they can either hurt competitors or be an instrument of collusion. Often, oneway and two-way access problems occur between the same firms. This happens in the case of unbundled network elements (UNEs). UNEs have been introduced by regulators in the US and some other countries (Germany) as a tool to facilitate entry in the local exchange and complement partial networks of entrants, potentially reducing wasteful duplication of facilities.

UNEs, while helping entrants and being a means of regulatory and competition policy (based on the essential facilities doctrine), therefore also have competition-reducing effects. First, they reduce excess capacity that could lead to fierce competition. Second, the price to be paid for UNEs is a cost to the entrant and a source of revenue to the incumbent (Laffont and Tirole 2000, Section 5.6). Thus, to the extent that UNEs are profitable, they make the incumbent compete less for retail customers. Incumbents, nevertheless, tend to oppose UNEs because they speed up entry that otherwise could be delayed or avoided altogether and because price regulation reduces profits from UNEs.

Entrants using UNEs often require the incumbent's termination services and the incumbent requires their termination services. As a result, UNEs represent a situation with both one-way and two-way access. Because of scale economies, at least one of the charges has to exceed marginal costs, in order to make the incumbent break even. Both, the termination charge and the UNE charges could then be used as a coordination device by the network providers. Because low termination charges preserve a level playing field without expropriating the incumbent, termination charges should be at or below marginal costs and the UNE charge above marginal costs (Laffont and Tirole 2000, Section 5.6). 


\section{Conclusions}

While the focus of this survey is on telecommunications, the principles it reviews could be relevant to other networks depending upon their particular characteristics. This is clearest for Internet peering, which resembles bill-and-keep. Electricity transmission grids, credit card networks and railroad tracks can be bottleneck facilities to which the one-way access model would apply. In fact, Baumol (1983) first formulated his version of the ECPR for a railroad example. Nevertheless, because many results of this survey are not rebust to fairly small changes in the underlying assumptions, a main lesson from our discussion is that the applicability of theoretical results to policy largely depends on the sector-specific properties incorporated in the models.

The survey considers only the pricing element of an interconnection contract, leaving aside other issues such as risk sharing ${ }^{43}$, transactions costs and technological agreements (standardization). It does not consider the direct or political economy costs of regulation. Even so, it reveals that the pricing issues have not been solved. Access and interconnection pricing can only be appraised in the wider context of the regulation and competition of the market as a whole. For example, the properties of the now-famous Baumol-Willig (ECPR) rule are different when there is a retail price cap than without it. It is critical for the special treatment of access pricing that there are natural monopoly elements in the network. Where these are absent or bypass is broadly viable access pricing will pose competition concerns only for special cases. These properties, however, are largely unknown to the regulator. One function of access charge rules therefore has to be to provide the right incentives for facilities-based competition and bypass. This involves an assessment of innovation and dynamic aspects that the current access pricing literature does not provide.

The normative results suggest that, for one-way access to bottleneck facilities, the two leading approaches to regulation appear to be global price caps or access price caps combined with deregulated retail tariffs. These approaches could include an imputation requirement related

\footnotetext{
${ }^{43}$ For a discussion of aspects of risk bearing in interconnection contracts see Lewis Evans and Neil Quigley (2000).
} 
to the Baumol-Willig rule. The survey emphasizes that two-way access is characterized by both potential exclusion and potential collusion, largely depending on asymmetries and on the type of downstream pricing. Since for the interesting case of economies of scale in the network, optimal interconnection charges could be above or below marginal costs, there is no simple optimal rule. Taken together, this suggests that, in a system with both one-way and two-way access, there might be access price caps, possibly with two baskets, one for one-way access and one for two-way access charges. This could reduce some of the cost measurement problems encountered, when basing access and interconnection charges on costs and it reduces the danger of premature deregulation of access and interconnection. At the same time, retail could be deregulated (possibly helped by a universal service policy as a second policy instrument). However, the consequences of price caps for two-way access need to be analyzed first and compared to other regulatory options, such as the COBAK approach or the board-to-board method. Such comparison should include the effects on intermodal competition, as bill-and-keep could improve the competitiveness of traditional phone services against Internet-based telephony. Further research is also badly needed about nonlinear access and interconnection charges, about asymmetries in interconnection and about the investment effects of different access and interconnection regimes.

As in any area of active research perceived gaps fairly quickly lead to new discoveries. The symmetric approach of L-R-T (1998a) with homogeneous consumers quickly led to new models with asymmetries between firms and with heterogeneous demands. The static approach of the models has given way to new dynamic approaches that emphasize entry and investment decisions. The old insight that incoming calls have value is finally bearing fruit in the two-way access models. It yet needs to be fully appreciated in the context of one-way access. For example, a local exchange carrier, providing call termination services to a long-distance carrier can benefit from the value of incoming calls by being able to increase subscription charges. It may thus have less of an interest in high access charges that reduce the volume of incoming calls. A similar incentive could hold for originating access charges, which are passed on into long-distance charges and therefore affect willingness to pay for subscription. These observations suggest that 
the FCC (2001) may be on the right track by looking for a unified approach to one-way and twoway access charges.

A final word on regulation and competition policy: Access and interconnection price regulation is very technical and requires an in-depth knowledge of the industry. This favors industry-specific regulation over antitrust agencies. However, as telecommunications competition matures, many of the technical problems will have been solved routinely, so that competition policy can take over. 


\section{References}

Acton, Jan and Ingo Vogelsang. 1992. "Telephone Demand Over the Atlantic: Evidence from

Country-Pair Data," J. Ind. Econ. 40, pp. 305-323.

Armstrong, Mark. 1997. "Mobile Telephony in the U.K.," mimeo, September.

Armstrong, Mark. 1998a. "Network Interconnection in Telecommunications," Econ. J. 108, pp. 545-564.

Armstrong, Mark. 1998b. "Local Competition in UK Telecommunications," in Regulating Utilities:

Understanding the Issues. Michael Beesley, ed. Institute of Economic Affairs.

Armstrong, Mark. 1999. "Regulation and Inefficient Entry: Economic Analysis and British Experience," mimeo, Nuffield College, November.

Armstrong, Mark. 2001. “Access Pricing, Bypass, and Universal Service," Amer. Econ. Rev. Papers Proceedings 91(2), pp. 297-301.

Armstrong, Mark. 2002. "The Theory of Access Pricing and Interconnection," in Handbook of Telecommunications Economics. Martin Cave, Sumit Majumdar, and Ingo Vogelsang, eds. Amsterdam: Elsevier Publishers, pp. 295-384.

Armstrong, Mark, Simon Cowan and John Vickers. 1994. Regulatory Reform - Economic Analysis and British Experience, MIT Press: Cambridge, MA, and London.

Armstrong, Mark, Chris Doyle and John Vickers. 1996. "The Access Pricing Problem: A Synthesis," J. Ind. Econ. 44, pp.131-150.

Armstrong, Mark and John Vickers. 1998. “The Access Pricing Problem with Deregulation,” J. Ind. Econ. 46, pp. 115-121.

Arnbak, Jens, Bridger M. Mitchell, Werner Neu, Karl-Heinz Neumann, and Ingo Vogelsang. 1994.

"Network Interconnection in the Domain of ONP," Final WIK/EAC Report of Study for the European Commission, Brussels, November.

Atkinson, Jay M. and Christopher C. Barnekov. 2000. "A Competitively Neutral Approach To Network Interconnection,” FCC Office of Plans and Policy Working Paper No. 34.

AT\&T. 1996. "Reply Comments of AT\&T Corp.,” CC Docket 96-98, May 30.

Baumol, William J. 1983. "Some Subtle Issues in Railroad Regulation," J. Transport Econ. 10, pp.1-2. 
Baumol, William J. and David F. Bradburd. 1970. "Optimal Departures from Marginal Cost Pricing," Amer. Econ. Rev. 60, pp.181-298.

Baumol, William J. and J. Gregory Sidak. 1994. Toward Competition in Local Telephony. Cambridge, Mass.: MIT Press and American Enterprise Institute Press.

Baumol, William J., Janusz Ordover and Robert Willig. 1997. "Parity Pricing and its Critics: A Necessary Condition for Efficiency in the Provision of Bottleneck Services to Competitors," Yale J. on Reg. 14, pp. 145-163.

Beard, T. Randolph, David L. Kaserman, and John W. Mayo. 1999. "Regulation, Vertical Integration, and Sabotage," mimeo.

Biglaiser, Gary and Patrick DeGraba. 2001. "Downstream Integration by a Bottleneck Input Supplier Whose Regulated Wholesale Prices Are Above Costs," RAND J. Econ. 32, pp. 302-315. Boiteux, Marcel. 1956. "Sur la Gestion des Monopols Public Astreints à Equilibre Budgetaire," Econometrica 24, pp. 22-40 [English translation: "On the Management of Public Monopolies Subject to Budget Constraints," J. Econ. Theory 3, 1971, pp. 219-240.]

Brock, Gerald W. 1995. "The Economics of Interconnection," Teleport Communications Group, Staten Island, New York, April.

Burton, Mark L., David L. Kaserman and John W. Mayo. 1997. "The Economics of Common Costs: Lessons from (and for) Regulatory Policy," Paper Presented at AEI Conference "Pricing and Costing a Competitive Local Telecommunications Network,” Washington, November 4.

Carter, Michael and Julian Wright. 1994. "Symbiotic Production: The Case of Telecommunications Pricing," Rev. Ind. Org. 9, pp. 365-378.

Carter, Michael and Julian Wright. 1999a. "Interconnection in Network Industries,“ Rev. Ind. Org. 14, pp. $1-25$.

Carter, Michael and Julian Wright. 1999b. "Bargaining Over Interconnection: The Clear-Telecom Dispute," Econ. Rec. 73, pp. 241-255.

Carter, Michael and Julian Wright. Forthcoming. “Asymmetric Network Interconnection,” Rev. Ind. Org.. 
Cave, Martin, H. Rood, Sumit Majumdar, Tommaso Valletti, and Ingo Vogelsang. 2001. "The Relationship between Access Pricing Regulation and Infrastructure Competition,” Report to OPTA and DG Telecommunications and Post.

Crew, Michael and Paul Kleindorfer. 1996. "Incentive Regulation in the United Kingdom and the United States: Some Lessons," J. Reg. Econ. 9, pp. 211-225.

De Bijl, Paul and Martin Peitz. 2003. Regulation and Entry into Telecommunications Markets. Cambridge, UK: Cambridge U. Press.

DeGraba, Patrick. 2000a. "Efficient Interconnection Regimes for Competing Networks," Paper presented at TPRC Conference, Arlington, Virginia, September 23-25.

DeGraba, Patrick. 2000b. "Bill and Keep at the Central Office As the Efficient Interconnection Regime," FCC Office of Plans and Policy Working Paper No. 33.

DeGraba, Patrick. 2002. "Bill and Keep as the Efficient Interconnection Regime?: A Reply," Rev. Network Econ. 1(1), pp. 61-65

De Fraja, Gianni. 1999. "Regulation and Access Pricing with Asymmetric Information," Eur. Econ. Rev. 43, pp. 109-134.

Dessein, Wouter. 1998. "Network Competition when Customers are Heterogeneous," mimeo, June 10.

Dessein, Wouter. 2001. "Network Competition in Nonlinear Pricing," mimeo, December.

Diamond, Peter A. and James A. Mirrlees, 1971. "Optimal Taxation and Public Production. I: Production Efficiencies. II: Tax Rules,” Amer. Econ. Rev. 61, pp. 8-27 and 261-278.

Domon, Koji and Koshiro Ota. 2001. “Access pricing and market structure," Information Econ. \& Pol. 13, pp. 77-93.

Economides, Nicholas. 1998. "The Incentive for Non-Price Discrimination by an Input Monopolist," Int. J. Ind. Org. 16, pp. 271-284.

Economides, Nicholas, Guiseppe Lopomo, and Glenn Woroch. 1996. "Strategic Commitments and the Principle of Reciprocity in Interconnection Pricing," mimeo.

Ergas, Henry and Eric Ralph. 1997. "Pricing Network Interconnection: Is the Baumol-Willig Rule the Answer?" Paper prepared for the Trade Practices Commission, Australia. 
Evans, Lewis T. and Neil C. Quigley. 2000. "Contracting Incentives for Breach and the Impact of Competition Law," World Competition, 23 (2).

FCC. 2001. "In the Matter of a Unified Intercarrier Compensation Regime," CC Docket No. 01-92, FCC 01-132, Federal Communications Commission, Notice of Proposed Rulemaking, Adopted: April 19, 2001.

Fuss, Melvyn A. and Leonard Waverman. 2002. "Econometric Cost Functions," in Handbook of Telecommunications Economics. Martin Cave, Sumit Majumdar, and Ingo Vogelsang, eds. Amsterdam: Elsevier Publishers, pp. 143-177.

Gabel, David and Richard Gabel. 1997. "The Application of Cost Data in the Telecommunications Industry," Paper Presented at the $25^{\text {th }}$ Telecom. Pol. Research Conference, Alexandria, Virginia, September 27-29.

Gans, Joshua S. and Stephen P. King. 2001. 'Using 'Bill and Keep' Interconnection Arrangements to Soften Network Competition," Econ. Let. 71, pp. 413-420.

Gasmi, Farid, Jean-Jacques Laffont, and William W. Sharkey. 1997. "Incentive Regulation and the Cost Structure of the Local Telephone Exchange Network,” J. Reg. Econ. 12, pp.5-25.

Gasmi, Farid, Jean-Jacques Laffont, and William W. Sharkey. 1998. "A Technico-Economic Methodology for the Analysis of Local Telephone Markets," in J.K MacKie-Mason and D. Waterman, Telephony, the Internet and the Media, Mahwah, NJ: Lawrence Erlbaum, pp. 15-36.

Guthrie, Graham, John Small and Julian Wright (2000), "Pricing Access: Forward Versus Backward Looking Cost Rules,” Working Paper, U. of Auckland.

Hahn, Jong-Hee. 1999. "Network Competition and Interconnection with Heterogeneous Subscribers," mimeo, Keele University.

Haring, John and Jeffrey H. Rohlfs. 1997. "Efficient competition in local telecommunications without excessive regulation," Information Econ. \& Pol. 9, pp. 119-132.

Hausman, Jerry A. 1997. "Valuing the Effect of Regulation on New Services in Telecommunications," Brookings Papers on Economic Activity - Microeconomics, pp. 1-38. Hausman, Jerry A. 2000. "The Effect of Sunk Cost in Telecommunications Regulation," in J. Alleman and E. Noam, Real Options: The New Investment Theory and its Implications for Telecommunications, Boston: Kluwer. 
Hausman, Jerry A. and Timothy J. Tardiff. 1995. "Efficient local exchange competition," Antitrust Bul. 40, pp. 529-556.

Hermalin, Benjamin E. and Michael L. Katz. 2001. "Network Interconnection with Two-Sided User Benefits," mimeo, Walter A. Haas School of Business, U. of California, Berkeley.

Hubbard, R. Glenn and William Lehr. 2000. "Telecommunications, the Internet and the Cost of Capital," in The Internet Upheaval. Ingo Vogelsang and Benjamin Compaine, eds. Cambridge, MA, and London: MIT Press, pp. 127-150.

Jeon, Doh-Shin, Jean-Jacques Laffont and Jean Tirole. 2001. "On the Receiver Pays Principle," mimeo, U. of Pompeu Fabra.

Kahn, Alfred E., Timothy J. Tardiff, and Dennis L. Weisman. 1999. “The Telecommunications Act at Three Years: An Economic Evaluation of its Implementation by the Federal Communications Commission," Information Econ. \& Pol. 11(4), pp. 319-366.

Kim, Jeong-Yoo and Yoonsung Lim. 2001. "An economic analysis of the receiver pays principle," Information Econ. \& Pol. 31, pp. 231-260.

Laffont, Jean-Jacques, Patrick Rey, and Jean Tirole. 1998a. "Network Competition: I. Overview and Nondiscriminatory Pricing," RAND J. Econ. 29, pp. 1-37.

Laffont, Jean-Jacques, Patrick Rey, and Jean Tirole. 1998b. "Network Competition: II. Price Discrimination," RAND J. Econ. 29, pp. 38-56.

Laffont, Jean-Jacques and Jean Tirole. 1993. A Theory of Incentives in Procurement and Regulation, Cambridge, MA: MIT Press.

Laffont, Jean-Jacques and Jean Tirole. 1994. “Access Pricing and Competition,” Eur. Econ. Rev. 38, pp. 1673-1710.

Laffont, Jean-Jacques and Jean Tirole. 1996. "Creating Competition Through Interconnection: Theory and Practice," J. Reg. Econ. 10, pp. 227-256.

Laffont, Jean-Jacques and Jean Tirole. 2000. Competition in Telecommunications, Cambridge, MA: MIT Press.

Lapuerta, Carlos and William B. Tye. 1999. "Promoting Effective Competition Through Interconnection Policy," Telecom. Pol. 23, pp. 129-145. 
Larsen, Alexander C. 1995. "Interconnection and Access Pricing: A Derivation of the EfficientComponent Pricing Rule," mimeo, Southwestern Bell Telephone Company, October.

Lehman, Dale E. and Dennis L. Weisman. 1996. "Telephone Pools and Economic Incentives," $J$. Reg. Econ. 10, pp. 123-146.

Lewis, Tracy R. and David E.M. Sappington. 1999. "Access pricing with unregulated downstream competition," Information Econ. \& Pol. 11, pp. 73-100.

Mandy, David M. 2000. "Killing the Goose That May Have Laid the Golden Egg: Only the Data Know Whether Sabotage Pays,” J. Reg. Econ. 17, pp. 157-172.

Mandy, David M. 2002. "TELRIC Pricing with Vintage Capital,” J. Reg. Econ. 22(3), pp. 215-250.

Masmoudi, Hautam and Francois Prothais. 1994. "Access Charges: An Example of Application of the Fully Efficient Rule - Mobile Access to the Fixed Network," mimeo, Ecole Politechnique and France Télecom, April.

Milgrom, Paul, Bridger M. Mitchell, and Padmanabhan Srinagesh. 2000. "Competitive Effects of Internet Peering Policies," in The Internet Upheaval - Raising Questions, Seeking Answers in Communications Policy. Ingo Vogelsang and Benjamin Compaine, eds. Cambridge, Mass., and London: MIT Press, pp. 175-195.

Mitchell, Bridger M., "Incremental Costs of Telephone Access and Use”. 1990. Report R-3909ICTF, RAND Corporation, Santa Monica.

Mitchell, Bridger M. 1993. First Affidavit "In the Matter of the Telecommunications Act 1984 and in the Matter of a Licence Granted by the Secretary of State for Trade and Industry to BT PLC Under Section 7 of the Telecommunications Act of 1984 Between Mercury Communications Limited (Plaintiff) and the Director General of Telecommunications (First Defendant) and British Telecommunications PLC (Second Defendant)" in the High Court of Justice, Queen's Bench Division, Commercial Court, 1993 Folio No. 2182.

Mitchell, Bridger M., Werner Neu, Karl-Heinz Neumann, and Ingo Vogelsang. 1995. "The Regulation of Pricing for Interconnection Services," in Toward a Competitive Telecommunication Industry. Gerald Brock, ed. Mahwah, NJ: Lawrence Erlbaum, pp. 95-118. Mitchell, Bridger M. and Ingo Vogelsang. 1998. "Markup Pricing for Interconnection: A Conceptual Framework," in Opening Networks to Competition: The Regulation and Pricing of 
Access. David Gabel and David F. Weiman, eds. Boston: Kluwer Academic Publishers, pp. 3147.

Noam, Eli. 2001. Interconnecting the Network of Networks, Cambridge, MA: MIT Press.

Noam, Eli. 2002. "Interconnection Practices," in Handbook of Telecommunications Economics. Martin Cave, Sumit Majumdar, and Ingo Vogelsang, eds. Amsterdam: Elsevier Publishers, pp. 385-421.

Perl, Lewis and Jonathan Falk. 1989. "The Use of Econometric Analysis in Estimating Marginal Cost," in Telecommunications Costing in a Dynamic Environment, Proceedings of the Bellcore Bell Canada Conference on Telecommunications Costing, Held 5-7 April 1989 in San Diego, pp. 825-846.

Reiffen, David. 1998. "A Regulated Firm's Incentive to Discriminate: A Reevaluation and Extension of Weisman's Results," J. Reg. Econ. 14, pp. 79-86.

Rohlfs, Jeffrey. 1979. “Economically-Efficient Bell-System Pricing.” Bell Laboratories Discussion Paper No. 138.

Salinger, Michael A. 1998. "Regulating Prices to Equal Forward-Looking Costs: Cost-Based Prices or Price-Based Costs," J. Reg. Econ. 14, pp. 149-164.

Sibley, David S. and Dennis L. Weisman. 1998a. "Raising Rivals' Costs: The Entry of an Upstream Monopolist in Downstream Markets," Information Econ. \& Pol. 10, pp. 451-470.

Sibley, David S. and Dennis L. Weisman. 1998b. "The Competitive Incentives of Vertically Integrated Local Exchange Carriers: An Economic and Policy Analysis," J. Pol. Anal. \& Management 17, pp. 74-93.

Shin, Richard T. and John S. Ying. 1992. "Unnatural Monopolies in Local Telephone," RAND J. Econ. 23, pp. 171-183.

Sidak, J. Gregory and Daniel F. Spulber. 1996. "Deregulatory Takings and Breach of the Regulatory Contract," N. Y. Univ. Law Rev. 71, pp. 851-999.

Valletti, Tommaso M. and Carlo Cambini. 2002. "Investments and Network Competition," mimeo, Imperial College Management School, London. 
Vogelsang, Ingo. 2000. "Regulation of Access to the Telecommunications Network in New Zealand:

A Review of the Literature," New Zealand Institute for the Study of Competition and Regulation, http://www.iscr.org.nz.

Vogelsang, Ingo. 2002. "Incentive Regulation and Competition in Public Utility Markets: A 20Year Perspective," J. Reg. Econ. 22(1), pp. 5-28.

Vogelsang, Ingo. 2003. "The Role of Price Caps in Bringing Competition to Network Industries," in Regulierung, Wettbewerb und Marktwirtschaft/Regulation, Competition and the Market Economy. Festschrift für C.C.v.Weizsäcker zum 65. Geburtstag. Hans G. Nutzinger, ed. Göttingen: Vandenhoeck \& Ruprecht,

Vogelsang, Ingo and Jörg Finsinger. 1979. “A Regulatory Adjustment Process for Optimal Pricing by Multiproduct Monopoly Firms,” Bell J. Econ. 10, pp. 157-171.

Vogelsang, Ingo and Bridger M. Mitchell. 1997. Telecommunications Competition: The Last 10 Miles, MIT Press and AEI Press.

Vogelsang, Ingo, in collaboration with Ralph-Georg Wöhrl. 2002. "Determining Interconnection Charges Based on Network Capacity Utilized," in Price Regulation. Karl-Heinz Neumann, Sonia Strube Martins and Ulrich Stumpf, eds. Bad Honnef: WIK Proceedings No.8.

Weisman, Dennis L. 1995. "Regulation and the Vertically Integrated Firm: The Case of RBOC Entry into Interlata Longdistance," J. Reg. Econ. 8, pp. 249-266.

Weisman, Dennis L.. 1998. "Regulation and the Vertically Integrated Firm: A Reply," J. Reg. Econ. 14, pp. 87-91.

Weisman, Dennis L. 2002. “The Efficient Component Pricing Rule: Friend or Foe?” mimeo, available at http://www.ksu.edu/economics/weisman/ecpr.pdf.

Willig, Robert D. 1979. "The Theory of Network Access Pricing," in Issues in Public Utility Regulation. Harry Trebing, ed. East Lansing: Michigan State U., pp. 109-152.

Woroch, Glenn A. 2002. "Local Network Competition," in Handbook of Telecommunications Economics. Martin Cave, Sumit Majumdar, and Ingo Vogelsang, eds. Amsterdam: Elsevier Publishers, pp. 641-716.

Wright, Julian. 2002a. "Bill and Keep as the Efficient Interconnection Regime?," Rev. Network Econ. 1(1), pp. 54-60. 
Wright, Julian. 2002b. "Access Pricing under Competition: an Application to Cellular Networks," $J$. Ind. Econ. 50(3), pp. 289-316. 